Competitividad y ventajas competitivas: revisión teórica y ejercicio de aplicación a 30 ciudades de México

\title{
Jaime Sobrino*
}

Las teorias tradicionales del comercio exterior no son capaces de explicar la evolución del intercambro comercial derivado del proceso de globalización, por lo que se han desarollado nuevas vetas explicativas, algunas de las cuales han enfatizado los conceptos de competencia y competitividad. De manera colateral, el tratamiento teórico del crecimiento económico local ha ido adoptando los nuevos arquetipos de la teoria del comercio internacional. El propósilo del presente artículo es discutir las principales aportaciones que han pugnado por explicar el significado de competencia y competitividad en la escala empresarial, de país y de ciudad, asi como los distintos postulados sobre los determinantes de la competitividad territorial o ventajas competitivas. La revisión de conceptos se complementa con una propuesia conceptual y operativa de los determinantes explicativos de la competitividad local y un ejercicio exploratorio de aplicación empínica sobre la competitividad industrial en 30 ciudades del pais.

Palabras clave: competencia, competitividad, ámbitos territoriales de la competitividad, ventajas comparativas

Fecha de recepción: 9 de mayo de 2001.

Fecha de aceptación: 29 de agosto de 2001.

\section{Competencia y competitividad}

En la enciclopedia internacional de las ciencias sociales se define la competencia como la rivalidad entre dos o más personas o grupos por conseguir determinado premio, y a menudo constituye un fin en sí misma. En la vida económica la competencia no es una meta sino una forma de organización de la actividad económica destinada a alcanzar una meta. El papel económico de la competencia consiste en disciplinar a los agentes para que suministren artículos y servicios de alta calidad y bajo precio.

La competencia es el aperitivo de la vida, pero en economía se considera el plato fuerte y cuerpo central organizativo de la teoría económica. Un mercado de competencia perfecta se caracteriza por que la producción de cada empresa es tan pequeña que no afecta el precio de mercado, suponiendo que los recursos son libres de mover-

* Profesor-investigador del Centro de Estudios Demográficos y de Desarrollo Urbano de El Colegio de México. Correo electrónico: 1jsobrin@colmex.mx 
se dentro de la economía, por lo que las empresas entran o abandonan libremente a la industria (Call y Holahan, 1985: 239-241). Según este modelo, todas las empresas son idénticas en funciones de producción, tecnología, costos, habilidades, localización y habilidades empresariales, y una empresa competitiva es aquella que maximiza sus beneficios en función de un precio de mercado dado; el volumen de producción competitivo es aquel cuyo costo marginal es igual al precio de mercado (o precio paramétrico) (Varian, 1994: 379).

Los elementos mencionados constituyen el punto de partida de la teoría del productor, considerando un escenario ideal de competencia perfecta que ha sido un método útil para analizar aspectos relevantes del comportamiento empresarial en el corto y largo plazos. Sin embargo, en vista de que la realidad se aleja de las premisas de este modelo, se han desarrollado otros como el de competencia pura que sólo mantiene el precio paramétrico y la libre entrada o salida (Samuelson, 1965: 82), o el de competencia monopólica, que se presenta cuando un conjunto de empresas que producen un bien dado disfruta de un poder de mercado que les permite fijar su propio precio (Varian, 1994: 445). Estos modelos mantienen, empero, el supuesto de igualdad técnica en el proceso productivo de cada empresa.

En el contexto actual de globalización y vertiginoso cambio tecnológico, la nueva competencia empresarial no significa maximizar los beneficios con la minimización de los costos, sino con la combinación de cuatro elementos principales: $i$ ) dirección de la empresa e innovaciones que se generan en el producto, en el proceso productivo, o en la organización interna; ii) tipos de coordinación en las fases de la cadena productiva; iii) organización de la industria en cuanto a competencia y cooperación, lo cual ocurre interfirmas o extrafirmas, y iv) elementos de una política industrial activa que coadyuva al uso creativo y formativo del mercado, enfoque de producción opuesto al de distribución y determinación de los sectores estratégicos para maximizar el crecimiento industrial (Best, 1990: 11-21).

Estos elementos introducen un planteamiento alternativo al concepto estático de competencia entre empresas, incorporando un enfoque dinámico que considera empresas con distintos grados de desarrollo técnico, dispersión de las rentabilidades individuales en cada grupo industrial, tendencia a la igualación de la rentabilidad media en todo el sector industrial por el libre movimiento del capital y nuevos factores para la localización territorial (Guerrero, 1996: 402). La empresa real compite de manera permanente por maximizar sus utilidades a partir de ajustes 
en su función de producción, adopción de innovaciones tecnológicas, oferta de nuevos productos y búsqueda de nichos de mercado.

Por otro lado, la competencia entre países ocurre para mejorar la participación de éstos en el comercio mundial y ha sido analizada por medio de las teorías del comercio internacional. Su precursor, Adam Smith, expuso que un país que tuviera empresas con ventaja absoluta en la producción de un bien determinado, gracias a sus menores costos tendría ventaja absoluta en el comercio internacional. Por su parte, David Ricardo enfocó su labor a determinar el impacto de la intermediación de los mecanismos monetarios, que incidirían en un patrón del comercio internacional no basado en el principio de ventajas absolutas, sino comparativas, el cual se define para cada país y para cada par de bienes como el menor precio relativo intersectorial, independientemente del nivel absoluto de los costos, y que estaría al alcance de países que incluso podrían estar en desventaja absoluta en ambos productos (Guerrero, 1996: 403).

El concepto de ventajas comparativas conlleva la especialización de la estructura productiva y de las exportaciones en un país; se sustenta, según el modelo de Hecksher-Ohlin, en el aprovechamiento de los recursos naturales y de la productividad relativa del trabajo entre los países que intercambian productos (Ramírez y Wallace, 1998: 17-19).

Un estudioso contemporáneo del comercio internacional, Michael Porter, enfatiza menos la ventaja comparativa como elemento estático que explica el intercambio y destaca más la ventaja competitiva que se relaciona con atributos específicos de los países, como dotación de factores, tecnología, producción con rendimientos crecientes a escala, diferenciación de productos y homogeneización en el patrón internacional de consumo (Porter, 1991: 38-40). Por otro lado, Paul Krugman se apega a la concepción neoclásica de David Ricardo y rescata el concepto de ventaja comparativa, pero ahora en función de la productividad relativa del trabajo y de los salarios relativos entre países, abandonando las diferencias en dotaciones de recursos naturales y economías de escala como factores del intercambio comercial (véase Krugman, 1991). Esto significa que la importación de bienes ocurre porque la productividad relativa del país exportador supera el salario relativo del importador.

Así, la competencia entre países pretende mejorar la participación de cada uno en el comercio internacional y para ello se utilizan mecanismos de política económica tales como ajustes en tasas de interés, tipo de cambio o tarifas arancelarias. 
Las formas más significativas de competencia entre ciudades ocurren por: i) inversiones privadas; ii) inversiones y fondos públicos para elevar el stock de satisfactores colectivos; iii) mercados para sus productos; iv) población que se traduce en capital humano, ingresos, poder político y ampliación de la demanda local, y $v$ ) organización de actividades de alto nivel (hallmark events) como juegos olímpicos (Gordon, 1999: 1001; y Lever, 1999: 1029). En cada caso la competencia puede ser entre muchas o pocas ciudades y en escalas regional, nacional, continental o global; en última instancia, las ciudades compiten para mejorar su posición en el sistema urbano nacional o internacional.

Para Krugman la competencia se da entre empresas y no entre países, y unas ciudades no compiten con otras, ya que sólo operan como áreas de localización de empresas que compiten entre sí (Krugman, 1994: 31). Por tanto, las economías de aglomeración (urbanización y localización) que ofrecen las ciudades sólo son condiciones generales necesarias para la producción, pero no suficientes para el éxito competitivo, y este último se relaciona con la competencia entre empresas que se fundamenta en la eficiencia de costos, innovaciones tecnológicas, actividades de mercadeo (marketing) y otros factores internos de la empresa (Krugman, 1996: 485-488).

En una posición un tanto contrastante, Porter establece que si bien las economías de urbanización (denominadas por él economías urbanas generalizadas) ya no son tan relevantes para el crecimiento económico local por el desarrollo generalizado de los sistemas de comunicación y la provisión de satisfactores colectivos, las economías de localización (o economías de aglomeración al nivel cluster) tienen una mayor influencia en la competencia local. Un cluster es un conjunto de empresas o industrias conectadas por relaciones especializadas de compraventa, elementos tecnológicos o habilidades, y los clusters no necesariamente se asocian con grandes ciudades (Porter, 1996: 85-86).

Las posiciones de Krugman y Porter ponen en la mesa del debate el papel de las economías de aglomeración como elementos de la competencia entre ciudades; el primero relega la importancia de éstas y el segundo enfatiza el rol de las economías de localización y que inducirían a la especialización de la estructura productiva local. A pesar de estas posturas, es indudable que los atributos particulares de las ciudades y la competencia entre ellas sí existe, por lo que hablar de competencia territorial en el contexto entre ciudades se remite a la existencia de recursos locacionales que generan economías externas 
de escala y alcance (scope) para firmas y sectores (Budd, 1998: 668), lo que se traduce en una rivalidad entre núcleos urbanos por atracción de inversiones, fondos públiços, turistas y actos de renombre.

De esta manera, las ciudades compiten por inversiones que generen empleos, por inversiones que coadyuven al crecimiento económico local, por inversiones con alta elasticidad-ingreso de la demanda, y por inversiones que favorezcan la producción sin atentar contra las condiciones ambientales. Lo anterior permite clarificar que las ciudades compiten en unos ámbitos y las empresas en otros; en algunos casos se advierte una línea muy fina entre la competencia de ambas, y en otros una clara sobreposición. El mayor problema de esta discusión es la solución empírica, ya que no es fácil el manejo y valoración de las variables de competencia y competitividad entre las ciudades, en contraposición a una situación relativamente más holgada para medirlas en el contex to empresarial.

Para un país las consecuencias de la competencia entre las ciudades que conforman su sistema urbano permanecen en la incertidumbre, lo cual ha propiciado el desarrollo de varios estudios en la materia (Lever y Turok, 1999: 792). En éstos se pretende demostrar alguna de las siguientes alternativas: $i$ ) es un juego de suma cero, o ii) es un juego que genera más valor agregado y por ende mayor beneficio a la economía en su conjunto gracias a los incrementos de la productividad local y la eficiencia en el uso de recursos.

Un juego se refiere al desarrollo de una situación de interacción entre diferentes individuos sujeta a reglas específicas y en la que se asocian pagos o beneficios vinculados a los posibles resultados. Un juego bilateral de suma cero ocurre cuando la suma de pagos o beneficios se mantiene constante para cualquier perfil de estrategias (Vega, 2000: 30). Los componentes de un juego son los siguientes: i) conjunto de jugadores; ii) orden de los sucesos (simultáneo o secuencial); iii) acciones posibles (o estrategias de juego); iv) información disponible (que depende del orden de los sucesos), y v) pagos o beneficios (Vega, 2000: 4-6).

Si se adaptan los componentes de la teoría de juegos a la competencia entre ciudades, entonces los jugadores son las ciudades; el orden de los sucesos generalmente es simultáneo porque si bien las ciudades actúan de manera independiente, lo hacen al mismo tiempo; las acciones posibles o estrategias individuales escenifican juegos no cooperativos y conforman un proceso a partir del papel activo de grupos locales para promover la localización de las actividades económi- 
cas; la estrategia de desarrollo se sustenta generalmente en la planeación estratégica donde se analiza la información disponible (Cheshire y Gordon, 1993: 3), y los beneficios se traducen en el desempeño competitivo, que puede ser medido por el crecimiento económico local, la creación de nuevas empresas, la generación de empleo, o medidas más complejas que incluyen equidad, distribución del ingreso, incremento en la calidad de vida de la población, y sustentabilidad del crecimiento económico.

Todo ello pone de manifiesto la importancia de distintos agentes para la promoción del crecimiento económico local y el uso de la planeación estratégica. Una vasta variedad de políticas se formulan ahora desde las localidades y regiones con poca injerencia del gobierno central, por lo que la descentralización y los gobiernos locales con visión empresarial son dos grandes elementos en la competencia por atraer inversiones; la mayor participación de los gobiemos locales en el crecimiento económico local ha sido uno de los grandes fenómenos en la ciencia regional desde la última década del recién concluido siglo xx (Malecki, 1997: 2).

Competencia y competitividad son conceptos relacionados pero no sinónimos, y en última instancia la segunda es consecuencia de la primera. El término competitividad forma parte de los fundamentos contemporáneos de las teorías del comercio internacional como consecuencia del papel creciente del proceso de globalización, pero también ha sido adaptado para el estudio económico de regiones y ciudades.

La competitividad se define por la capacidad de acceso de una empresa o territorio en el mercado doméstico o en el de exportación. Si la unidad de análisis aumenta su participación en el mercado doméstico o en el comercio internacional, entonces su competitividad habrá mejorado (Márquez, 1994: 101). La competitividad es una medida relativa que compara el desempeño económico de alguna unidad de análisis con el resto de unidades que forman el universo de estudio; es también un atributo que no puede ser medido directamente, por lo que se deben seleccionar una o algunas variables que asumen el papel de indicadores de competitividad. La unidad de análisis será competitiva en relación con otras èn función del crecimiento del indicador o indicadores seleccionados y durante un periodo específico de tiempo (Kresl y Singh, 1999: 1018).

La competitividad de un país consiste en sostener y expandir su participación en los mercados internacionales, al tiempo de elevar el nivel de vida de su población (Fajnzylber, 1988: 13). Porter y Krugman 
establecen que la productividad es el elemento fundamental de la competitividad de un país; para el primero la competitividad no se hereda, sino se crea, y está en función, como primer elemento, de la capacidad de su sector industrial para adoptar innovaciones tecnológicas que se traducen en un incremento de la productividad (Porter, 1991: 29), mientras que el segundo argumenta que cuando se rompen las barreras al comercio internacional, en un primer momento la localización de las actividades económicas tiende a concentrarse en el territorio central debido a consideraciones de acceso a mercados, lo que propicia una agudización de las desigualdades. Esta concentración de actividades en el centro se va compensando en el tiempo por diferenciales en el precio de los factores entre el centro y la periferia, lográndose en el límite una convergencia en la localización de actividades entre el centro y la periferia. Con ello, la competitividad entre los países no es un proceso monotónico y los salarios reales y la productividad de la periferia pueden seguir una trayectoria con forma de "u" durante el proceso de integración, aunque no siempre se sabe en qué lado de la curva se está al inicio del proceso integrativo (Krugman y Venables, 1990).

El comportamiento de las exportaciones y el balance en la cuenta corriente constituyen dos indicadores principales de la competitividad de un país (Malecki, 1997: 15), pero existen otros más, como por ejemplo: i) la tasa de cambio real basada en índices de precios al consumidor; ii) el costo unitario de la mano de obra; iii) la comparación entre los precios de los bienes comercializados y los de los domésticos, y $i v$ ) la participación de los sueldos y salarios en el valor agregado (Marsh y Tokarik, 1994). Por su parte el INEGI utiliza los siguientes indicadores de la competitividad de la economía mexicana: $i$ ) tasas de interés; ii) costo unitario y total de la mano de obra; iii) crecimiento de la productividad parcial del trabajo; $i v$ ) promedios arancelarios entre México y Estados Unidos, y $v$ ) cambio de la participación de las exportaciones mexicanas en los mercados de Estados Unidos y de la Unión Europea (INEGI, 1995).

El concepto de competitividad urbana alude a la capacidad de una ciudad para penetrar en los mercados local y de exportación, y a si relación con el crecimiento económico local y el incremento de la calidad de vida de sus residentes. Interesa la relación entre la capacidad de penetración del mercado y su vinculación permanente con el bienestar (Millán, 1996: 22). Otra definición de competitividad urbana se refiere al grado en el cual las ciudades pueden producir bienes y 
servicios para los mercados regional, nacional e internacional, aumentando de manera paralela el ingreso real y la calidad de vida de la población y procurando un desarrollo sustentable (Lever y Turok, 1999: 792). Lo anterior tiene que ver con la estructura económica local, los beneficiarios del crecimiento y la durabilidad del mismo.

Si la tasa de crecimiento de las actividades económicas en una ciudad (medida en términos de empleo o producto) es mayor respecto a otras que conforman el sistema urbano nacional, entonces se concluye que su competitividad o su posición son atractivas para hacer bienes, proveer servicios y comprar bienes y servicios. Una noción más rica sobre los indicadores de competitividad de una ciudad incluye seis atributos: $i$ ) creación de empleos con calificación y altos salarios; ii) producción de bienes y servicios que no atenten contra el ambiente; iii) producción de bienes y servicios con alta elasticidad-ingreso de la demanda; $i v)$ crecimien to económico en relación con el comportamiento del mercado de trabajo; $v$ ) tendencia a la especialización sectorial, y vi) tendencia a mejorar su posición en el sistema urbano nacional (Begg, 1999: 801-804).

Así, el análisis de la competitividad de un país o una ciudad se realiza generalmente con el uso de indicadores que miden el cambio relativo de la participación en los mercados, aunque cabe mencionar que así como ningún indicador puede ser considerado el mejor, el uso de indicadores de competitividad sólo es una parte del análisis, siendo la otra el estudio de los determinantes de la competitividad, los cuales serán tratados a continuación.

\section{Ventajas competitivas para un país}

Los indicadores de competitividad representan medidas cuantitativas del éxito competitivo de una unidad de análisis, pero no son variables explicativas de tal desempeño; las variables explicativas se denominan factores o determinantes de la competitividad y también ventajas competitivas.

El de ventaja competitiva es un concepto más empresarial que económico y hace referencia a un instrumento activo o a un proceso dinámico de acumulación de factores internos y externos para la producción. Dicha ventaja no es absoluta ni permanente, por lo que se gana y se pierde en función de las acciones o estrategias de juego de los competidores. Esto es congruente con lo establecido por Porter, 
quien sostiene que las ventajas competitivas de una unidad productiva se obtienen por un conjunto de elementos que pueden ser primarios y de soporte; los primarios corresponden a la logística interna y externa del proceso productivo, mientras que los segundos incluyen la infraestructura de la firma, el manejo de los recursos humanos y la adopción de innovaciones tecnológicas (Porter, 1997: 4-11).

Las ventajas competitivas no son realizables en economías cerradas, altamente protegidas y oligopolizadas. Cada unidad de análisis tiene que competir dentro de los mercados doméstico y foráneo, y en un gran número de casos el aprendizaje doméstico propicia el desarrollo de su competitividad internacional (Beristain, 1991: 97-99).

En la literatura se distinguen por lo menos tres propuestas distintas sobre las ventajas competitivas para un país. La primera es encabezada por Krugman y sostiene que los factores decisivos para la competitividad de una nación son internos a la empresa y no externos que puedan alterarse fácilmente y a corto plazo con una adecuada política económica. Según esta versión, en el comercio internacional operan tanto las fuerzas de equilibrio como otras fuerzas más o menos automáticas que aseguran que cualquier país se mantenga en condiciones de vender ciertos bienes en los mercados mundiales. La productividad es la fuerza de equilibrio fundamental para el desempeño competitivo de un país, y aquel que presente menos productividad que sus socios comerciales en todos los sectores se verá obligado a competir con base en el tipo de cambio (menor salario relativo), quedando éste como una segunda fuerza de equilibrio.

Asimismo, las fuerzas más o menos automáticas se encargan de que un país goce de competitividad en industrias con ventajas comparativas. Estas fuerzas le conceden una firme presencia en el intercambio mundial y son resultado de "economías externas" que permiten fortalecer la posición sólida de la industria. Estas economías externas se manifiestan de dos maneras: i) tecnológicas, que implican la derrama de conocimientos entre empresas (o la difusión de innovaciones), y ii) pecuniarias, que dependen del tamaño del mercado y la demanda ocupacional. De esta manera, la importancia de las fuerzas automáticas es evidente en la especialización in terregional y las ventajas comparativas pueden generarse de manera no exógena, lo que representa un caso potencial para la intervención del Estado (Krugman, 1992: 8-17).

La segunda propuesta se identifica con Porter y menciona que la ventaja competitiva se crea y mantiene mediante un proceso altamen- 
te localizado. Las ventajas competitivas adoptan un modelo de diamante de cuatro aristas que incluye elementos microeconómicos, derivados de las estrategias competitivas de las empresas (véase Porter, 1993: 55-67), y macroeconómicos que se establecen por el comportamiento del comercio internacional. Las esquinas del diamante se definen por los siguientes determinantes competitivos: i) condiciones de los factores, que tienen que ver con la oferta de mano de obra especializada o capital humano, infraestructura y creación y dotación de factores; ii) condiciones de la demanda, en función de la composición de la demanda interna y del comportamiento de la demanda exterior; iii) condiciones de los sectores conexos y de apoyo, en cuanto al acceso oportuno y eficaz a los principales insumos, unidades para coordinar o compartir actividades en la cadena productiva y conformación de cluster de actividades, y $i v$ ) condiciones de estrategia, estructura y rivalidad de la empresa, referentes a cómo se crean, organizan y gestionan las compañías y la naturaleza de la rivalidad doméstica (Porter, 1991: 110-181) (véase la figura 1).

FIGURA 1

Determinantes de la ventaja nacional

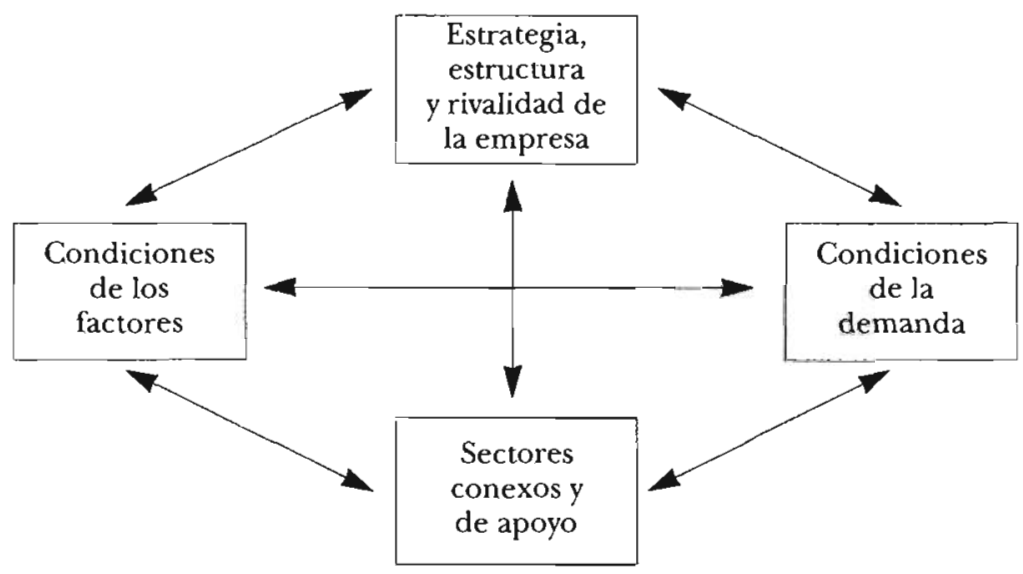

Fuente: Porter (1991: 111). 
Para Porter el papel del gobierno en la ventaja competitiva nacional consiste en influir en los cuatro determinantes. Su intervención es parcial y positiva o negativa porque carece de la capacidad de crearlas por sí mismo (Porter, 1991: 180-185). Sin embargo, es más conveniente ubicar al gobierno como un determinante más dentro del diamante, ya que su influencia es directa, como en la construcción de condiciones generales de la producción, o indirecta mediante la formulación de la política económica e industrial o en las acciones desempeñadas para la regulación económica y la estabilidad política.

El tercer enfoque se deriva de la posición de la UNCTAD y su punto de partida es convergente con el de Krugman en el sentido de sostener que la firma individual (su habilidad empresarial) es la que en última instancia genera el desempeño competitivo de un país. La agregación de las empresas conduce a la competitividad de la industria, de la región y del país en su conjunto. Los determinantes que influyen en el desempeño competitivo son: $i$ ) el mercado de factores; $i$ ) las instituciones con las que se interactúa, y iii) la estructura de incentivos (UNCTAD, 2000: 4) (véase la figura 2).

\section{FIGURA 2}

Triángulo de competitividad nacional

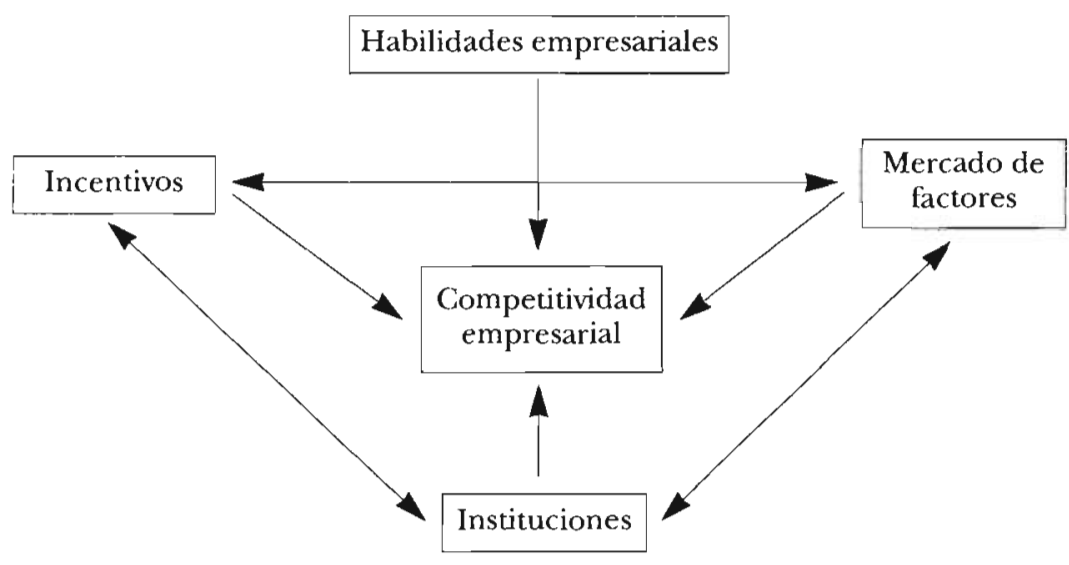

Fuente: UNCTAD (2000: 5). 
Las habilidades empresariales giran en torno a las acciones adoptadas en el interior de las empresas para incrementar su productividad y adecuar innovaciones tecnológicas (Unger, 1993: 183). El mercado de factores se relaciona con las habilidades de la fuerza de trabajo, el acceso a las innovaciones tecnológicas y la existencia de clusters de proveedores. Las instituciones abarcan los servicios de educación, capacitación, soporte tecnológico y financieros. Finalmente los incentivos se refieren a las políticas económica, comercial e industrial.

Bajo esta perspectiva, y en contraposición a Porter, las políticas públicas se constituyen en pilares de la competitividad de un país al ofrecer estabilidad macroeconómica y promover la eficiencia microeconómica. En materia microeconómica las acciones se concretan hacia la promoción de la apertura comercial, los estímulos al desarrollo tecnológico, la desregulación económica y la política industrial (Noyola, 1991: 25-28). Una política industrial que fomente la competitividad microeconómica se compone por tres elementos: $i$ ) acciones dirigidas a facilitar bajos costos de producción, lo que no significa necesariamente la imposición de topes salariales; ii) acciones para facilitar la transmisión de costos a precios eliminando obstáculos y regulaciones, y iii) acciones concebidas para actuar sobre factores distintos a los costos de producción como las estrategias de mercadotecnia y diferenciación de productos (Guerrero, 1996: 405-407).

Como corolario de los tres enfoques anteriores, la competitividad de un país está en función de la eficiencia microeconómica de sus empresas, de las políticas gubernamentales para promover el crecimiento económico, y del desempeño de sus principales ciudades para atraer nuevas inversiones que generan empleos y coadyuvan al crecimiento económico local. La competitividad se evalúa con indicadores cuantitativos monetarios, pero dichos indicadores se deben contrastar con el cambio en las condiciones de vida de la población.

Se han desarrollado varios ejercicios empíricos para evaluar la competitividad de las naciones utilizando indicadores de la misma o adoptando uno o más enfoques de ventajas competitivas. La revista The Economist utiliza la tasa de cambio real para medir la competitividad exportadora de una nación, y sus estudios indican que entre 1990 y 1997 los países que lograron una mayor depreciación de sus monedas fueron Corea del Sur, Indonesia, Taiwan y Tailandia (The Economist, 1998: 110). Por su parte, la CEPAL formuló un indicador denominado CAN (siglas en inglés de Análisis de Competitividad de las Naciones), que emplea como variable las exportaciones de un país 
por tipo de bien y se ampara en el concepto de ventajas comparativas reveladas, el cual compara en un punto del tiempo la participación de un bien específico en el mercado mundial y la participación de un país en las exportaciones mundiales (Casar, 1994: 347). La ventaja comparativa revelada indica los grupos en que se especializan las exportaciones de un país, por lo que el éxito de la apertura comercial depende no sólo de su magnitud sino también del tipo de especialización logrado (Guzmán, 1997: 189).

Con base en lo anterior, el estudio de la CEPAL supone que la competitividad de un país en el comercio internacional es producto de dos elementos: i) posicionamiento, que se refiere al dinamismo de un bien o grupo de actividad en las importaciones mundiales, y ii) eficiencia, respecto a la participación de un país en las exportaciones de ese bien o grupo de actividad en cuestión. A partir del comportamiento de estos dos elementos se construye una matriz de competitividad que distingue cuatro situaciones: $i$ ) estrellas ascendentes; $i$ i) estrellas menguantes; iii) oportunidades perdidas, y $i v$ ) retroceso (véase CEPAL, 1995).

Una aplicación del método CAN para países que exportaron entre 1980 y 1993 a naciones pertenecientes a la OCDE mostró que México, China, Japón y Taiwan fueron los principales países ganadores, y que México concentró $86 \%$ de sus exportaciones en bienes ascendentes, $8 \%$ con oportunidades perdidas, $4 \%$ en estrellas menguantes o situación vulnerable, y sólo $2 \%$ en bienes en retroceso (Sección Internacio nal, 1995: 624-626). Otro estudio determinó que entre 1986 y 1994 se ubicó $49 \%$ de las exportaciones de México en el rango de estrellas ascendentes, $25 \%$ menguantes, $11 \%$ con oportunidades perdidas y $15 \%$ en retroceso; los bienes que dominaron las tres primeras situaciones corresponden a la división de maquinaria y productos eléctricos y electrónicos, en tanto las oportunidades perdidas se debieron en mayor grado al petróleo y combustibles. Los resultados concluyen que el país ha ido especializando su estructura productiva y exportadora de acuerdo con las tendencias internacionales (Mattar, 1996: 193-202).

Por su parte, el International Institute for Management Development (IMD) publica desde 1997 un anuario mundial de competitividad que él mismo considera como el estudio más renombrado en el contexto internacional sobre la competitividad de las naciones. Partiendo del supuesto de que la competitividad de un país y de una empresa son conceptos interdependientes, el estudio mide y compara las condiciones que un país proporciona a sus empresas y la eficiencia 
de éstas. En su estudio de 2001 se presentó la posición competitiva de 49 naciones: las 30 pertenecientes a la OCDE y 19 denominadas economías de industrialización reciente o emergentes. La metodología consiste en utilizar 224 criterios que se ordenan jerárquicamente y se agrupan en cuatro factores principales y cinco subfactores en cada uno: i) desempeño económico (economía doméstica, mercado internacional, inversión extranjera, empleo y precios); ii) eficiencia gubernamental (finanzas públicas, política fiscal, marco institucional, ambiente para la creación de negocios y provisión de servicios educativos); iii) eficiencia empresarial (productividad, mercado de trabajo, mercado financiero, prácticas gerenciales e impacto de la globalización), y iv) infraestructura (básica, tecnológica, científica, de salud y sistema de valores).

Los resultados muestran que desde el inicio de la publicación Estados Unidos y Singapur ocupan el primero y segundo puestos, en tan to que para 2001 el tercero le correspondía a Finlandia, el cuarto a Luxemburgo y a Holanda el quinto. México fue ubicado en la posición 36 al obtener un rango 36 en desempeño económico, 27 en eficiencia gubernamental, 38 en eficiencia empresarial y 42 en infraestructura (véase Institute for Management Development, 2001).

Otros estudios comparan el grado de apertura comercial o globalización de un país, que en última instancia estaría vinculado con su posición competitiva en el intercambio internacional. Uno de ellos es el índice de libertad económica que utiliza 10 factores, cada uno de los cuales recibe una calificación de 1 a 5 , y se obtiene el índice con el promedio simple de las 10 evaluaciones. Los factores que utiliza son: i) políticas hacia la apertura comercial; ii) política fiscal; iii) intervención gubernamental en la economía; $i v$ ) política monetaria; v) flujos de capital e inversión extranjera; vi) sector bancario y financiero; vii) salarios y controles de precios; viii) derechos a la propiedad; $i x$ ) regulación y $x$ ) mercado negro y comercio informal. Con estos factores, en 1998 Hong Kong encabezó la lista de 154 países, seguido por Singapur, Bahrein, Nueva Zelanda y Suiza. México ocupó la posición 88 debido fundamentalmente a los efectos de la crisis financiera de finales de 1994, que propició una elevada inflación y problemas en el funcionamiento del sector bancario y en las operaciones financieras (Johnson, Holmes y Kirkpatrick, 1998: 245-246).

Por último, la firma A.T. Kearney publicó en el ejemplar de enero-febrero de 2001 de la revista Foreign Policy un artículo sobre el grado de integración de 50 países al proceso de globalización, definido 
por la conjugación de niveles de integración económica (participación en el comercio mundial), uso de internet, nivel de contactos personales (viajes, llamadas telefónicas y envios internacionales) y flujos de capital (inversión extranjera directa y en cartera). Con base en ello, Singapur fue el país más globalizado, seguido por Holanda, Suecia, Suiza y Finlandia; Canadá apareció en el décimo lugar y Estados Unidos en decimosegundo, en tanto que el país mejor situado en Latinoamérica fue Chile en la posición 26 y México se ubicó en la 39 . El estudio también establece que la medición del nivel de globalización por país no está exento de ironía, pues a menudo muchas de las naciones menos integradas están siendo arrastradas a la globalización por fuerzas ajenas a su voluntad (Notimex, 2001).

Los estudios descritos muestran la interconexión entre la teoría y los ejercicios empíricos de la competitividad de las naciones, así como la diversidad de criterios empleados en los segundos. Para la CEPAL la evidencia de competitividad está en la cuota de mercado que cada país gana para sus productos de exportación; The Economist se aboca al comportamiento del tipo de cambio real, y tanto el IMD como los concernientes al grado de integración al proceso de globalización ponderan una serie de indicadores que son manejados en los enfoques de ventajas competitivas.

Si se retoma el modelo de la CEPAL para el caso de México se concluye que éste ocupa una posición como país ganador en el concierto mundial, lo que se explica por el comportamiento de sus exportaciones, que pasaron de 22.6 a 121.8 miles de millones de dólares entre 1980 y 1997, lo que le permitió mejorar su participación de 1 a $1.8 \%$ del comercio mundial para los mismos años (The World Bank, 2000: 259). Sin embargo, tal posición no se explica del todo con la medición de sus ventajas competitivas o su grado de integración al proceso de globalización. De manera adicional, los ejercicios empíricos sólo adoptan la mitad del concepto de competitividad (capacidad de penetración de un país en el comercio internacional), dejando de lado la otra mitad que alude al mejoramiento de la calidad de vida de la población. A lo más esto último se considera como una variable explicativa.

Por lo anterior, los estudios empíricos deben tomarse como punto de partida para un análisis más profundo sobre las especificidades competitivas de un país y proponer medidas cuantitativas que contrasten el éxito competitivo exterior con su capacidad endógena de crecimiento y el impacto en las condiciones de vida de la población. Es muy probable que esto último se omita consistentemente en los ejercicios empíri- 
cos porque la única generalización que se puede hacer es que el proceso de globalización ha propiciado una mayor desigualdad e inestabilidad social (Gilbert, 1998: 174), que se observa en las virulentas manifestaciones ocurridas en las cumbres del Foro Económico Mundial.

\section{Determinantes de la competitividad de una ciudad}

Los factores explicativos de la competitividad local son adaptaciones de los enfoques sobre ventajas competitivas de las naciones y de las proposiciones de las teorías de localización de las actividades económicas. Porter establece que las razones por las que una ciudad alcanza un éxito competitivo quedan comprendidas dentro de las mismas consideraciones incorporadas en el diamante de cuatro aristas de la gráfica 1 (Porter, 1991: 218), en tanto que de la teoría de localización de las actividades económicas se han rescatado las propuestas normativas de costo mínimo determinadas por los costos del transporte, de la mano de obra y de las economías de aglomeración; los resultados de los modelos de comportamiento que enfatizan la relación entre el tamaño de la empresa y la toma de decisiones, y los estudios sobre la organización industrial y la flexibilización del proceso productivo (véase Chapman y Walker, 1991 y Ramírez y Hauser, 1996).

Es claro que la economía urbana difiere en muchos aspectos de la economía de un pais, por lo que la adaptación del enfoque de ventajas competitivas al contexto local debe abarcar al menos seis elementos: i) los gobiernos locales tienen muy poca injerencia en la formulación de las políticas macroeconómicas de un país; ii) el trabajo y el capital tienen una mayor movilidad a escala local; iii) las economías urbanas dependen más del comportamiento de los actores y las agencias externos a la ciudad; iv) en el contexto local la competitividad de una ciudad se analiza en función del cambio en la participación de alguna variable macroeconómica en el contexto nacional; $v$ ) es necesario tomar en cuenta el papel de las políticas regionales adoptadas por el gobierno central, y vi) los gobiernos locales tienden a desempeñar un rol más importante en la promoción del crecimiento económico local.

La revisión de la literatura sobre factores empíricos de competitividad local permite concluir que hasta el momento no se cuenta con algún o algunos enfoques que se distingan por haber concitado consenso o tener mayor uso. A continuación se mencionan tres metodologías que a juicio de quien escribe resultan ser las más significativas. 
La primera aplicó el enfoque de Porter sobre las ventajas competitivas para entender el tránsito de Coventry -una localidad británica de 300000 habitantes severamente afectada en la Segunda Guerra Mundial-, de relativa desventaja competitiva en los setenta a una posición competitiva a partir de la mitad de los ochenta del siglo Xx. Las condiciones de los factores y de la demanda se ubicaron como factores concernientes con el espacio (environment), y en el primero se analizaron los cambios en el costo y disponibilidad de tierra, trabajo y capital, en tanto que las condiciones de la demanda se estudiaron con un modelo de cambio y participación utilizando la variable empleo. La estrategia de la empresa y los sectores conexos y de apoyo se denominaron factores concernientes con la organización (management) y para el primero se detalló el tamaño de los establecimientos, en tanto que en el segundo se investigó la conformación de clusters de actividades (Healey y Dunham, 1994: 1279-1301).

La segunda aportación establece que los factores de competitividad local en el corto plazo son distintos a los del largo plazo; en el primero la base competitiva está determinada por la estructura económica local, el carácter y efectividad de sus instituciones y la calidad y cantidad de la infraestructura (en otras palabras, por sus economias de urbanización y de localización que se traducen en la especialización de su estructura económica), mientras que en el largo plazo dicha base competitiva se sustenta por la adopción de innovaciones tecnológicas y la formación de capital humano, de ahí que la inversión en capital físico y humano permita consolidar y aumentar las ventajas competitivas locales.

A su vez, y retomando los postulados de Krugman, esta propuesta sostiene que las ventajas locales se dividen en directas o internas a la firma, en relación con los costos de operación, e indirectas o externas y relacionadas con el ambiente local y la influencia del sistema urbano nacional. Por último se menciona que otra fuente de ventaja competitiva es el papel de los gobiernos locales y el establecimiento de políticas convenientes (Begg, 1999: 796-800).

La tercera propuesta de relevancia establece que la competitividad local es producto de determinantes económicos y estratégicos. Los determinantes económicos incluyen los factores de la producción, la infraestructura, la localización, la estructura económica y las amenidades; todos ellos son cuantitativos. Los determinantes estratégicos abarcan la efectividad de los gobiernos locales, la estrategia urbana, la cooperación entre los sectores público y privado y la flexibili- 
dad institucional; todas estas son fuerzas cualitativas (Kresl, 1995: 4568). De manera adicional se establece que los determinantes estratégicos se relacionan con la adopción de la planeación estratégica que permite poner en práctica políticas e iniciativas para seguir la orientación más beneficiosa de la estructura económica local: i) expansión cuantitativa de su estructura productiva básica, o ii) reestructuración cualitativa de sus actividades (Kresl, 1998: 695-703).

A la par de las tres posiciones empíricas anteriores, otros autores establecen propuestas un poco más aisladas poniendo énfasis en la distribución y eficiencia de los sistemas de transporte, las características del mercado de trabajo y la imagen e identificación de la propia ciudad en cuanto a la conservación de sus espacios históricos, el desarrollo de actividades culturales y la reactivación de su centro tradicional (Busquets, 1993: 166); refiriéndose al cambio tecnológico y a la calidad de las universidades que permiten enriquecer el capital humano y el stock de conocimientos (Malecki, 1997: 33), o interrelacionando el papel de las políticas con el comportamiento de las empresas, en donde la nueva política urbana tiene que ver con las estrategias asumidas por los gobiernos locales para promover el crecimiento en función de la atracción de inversiones, lo que adquiere una connotación económica pero también política y urbanística (Cox, 1995: 213-224).

Las aportaciones reseñadas sobre los factores que explican la competitividad local permiten establecer al menos tres conclusiones: $i$ ) la diversidad de variables empíricas que se utilizan como determinantes competitivos; ii) la oscura relación entre competitividad y calidad de vida, y iii) el papel de los gobiernos locales en el fomento de la competitividad. La primera da pauta para establecer una propuesta de ventajas competitivas locales por parte de quien suscribe, misma que será reseñada y ejemplificada empíricamente para el crecimiento industrial de 30 ciudades del país entre 1988 y 1998 en el siguiente apartado. Antes de culminar éste, se hablará un poco sobre las otras dos.

Calidad de vida y bienestar social son conceptos estrechamente interrelacionados; el primero alude al conjunto de características físicas, biológicas, psicológicas y sociales que alcanza una población, en tanto que el segundo atañe al grado de satisfacción fisica y mental de la colectividad. Los indicadores más significativos para el estudio del bienestar social incluyen: $i$ ) alimentación; ii) niveles de educación formal; iii) condiciones de salud, y iv) situación material de la vivienda. Las disparidades de la calidad de vida son producto de diversos facto- 
res entre los que sobresalen los niveles diferenciales de ingreso, el acceso a oportunidades ocupacionales, la localización de las actividades económicas, la dotación de equipamiento e infraestructura y las políticas de mejoramiento urbano (Moreno, 1995: 511-512).

No es lo mismo hablar de calidad de vida que de necesidades sociales. La calidad de vida se refiere a las condiciones existentes de bienestar, mientras que las necesidades se relacionan con el nivel mínimo de provisión y acceso a la población en los rubros de alimentación, vestido, vivienda, educación y salud. Existe un desfase entre el crecimiento urbano (necesidades sociales) y la capacidad de respuesta de la oferta de servicios públicos para encarar las necesidades de la población (calidad de vida); este desfase propicia una amplia diferenciación en el bienestar social tanto entre ciudades como en el interior de la misma.

Mencionamos ya que la competitividad se refiere a la interconexión entre el desempeño económico y el incremento en la calidad de vida de la población. Un punto de vista al respecto sostiene que las localidades presentan una pirámide competitiva en cuya punta se ubica la calidad de vida, que depende del empleo y la productividad, las cuales a su vez están sustentadas por las ventajas competitivas de la localidad. El empleo recibe la influencia de varios factores que inciden tanto en su oferta (tamaño de la ciudad, composición por edades, crecimiento demográfico y niveles educativos) como en su demanda (función de producción, inversiones productivas, innovaciones tecnológicas, ingreso de la población y cambios en la demanda de bienes y servicios) (Hirsch, 1977); por otro lado, la productividad depende de las innovaciones, los impuestos y la inversión (Begg, 1999: 798).

Pero tal y como ocurre en la formulación de ventajas competitivas de las naciones, la calidad de vida también se interpreta como una parte del perfil competitivo de una ciudad o como un determinante de la misma. Esto se apoya en el papel cambiante de la espacialidad en la sociedad contemporánea, siendo que el capitalismo actual es más sensitivo a la calidad diferenciada de lugares, de ahí que exista una perspectiva de las élites que controlan la conformación de estos espacios para su rediseño y reposicionamien to (Harvey, 1989: 295). Por lo anterior el gobierno local cada vez está más relacionado con las condiciones urbanas suficientemente atractivas para atraer inversiones y la calidad de vida de una ciudad opera como fuerza competitiva al fomentar la atracción de capitales y de población con determinadas características (Rogerson, 1999: 971-975). 
Veamos por último el papel del gobierno en la competitividad local. El gobierno central asume tres funciones principales: $i$ ) estabilización, por medio de la política monetaria; ii) localización, con la provisión de servicios públicos, y iii) distribución, a partir del reparto del gasto público. Con el desarrollo de estas funciones el gobierno puede crear las bases organizacionales de la competencia territorial gracias a la procuración de estabilidad económica, a la promoción de la eficiencia microeconómica y a la provisión de condiciones generales para la producción y servicios públicos. De manera más específica, el gobierno central contribuye a la competitividad nacional con la adopción de políticas abocadas al fomento del comercio exterior y a la atracción de inversión extranjera. Una herramienta fundamental es el diseño y operación de una política industrial activa que incluya medidas que estimulen la inversión y la especialización sectorial, así como acciones regulatorias que incidan en el comportamiento de las fuerzas del mercado (Dicken, 1992: 157-159).

La evolución de la intervención del gobierno central en el crecimiento económico local en los países desarrollados ha seguido un proceso histórico lineal que ha ido desde la priorización de la política regional durante la primera mitad del siglo $\mathrm{xx}$, pasando por la formación de autoridades para la planeación metropolitana, por la ejecución de acciones para la ordenación del sistema urbano nacional en los setenta, y por las políticas de rescate de la ciudad central en los ochenta (Bovaird, 1992: 355-357). Con el carácter cambiante del gobierno central, los gobiernos locales han asumido recientemente nuevas funciones, dejando de ser sólo instrumentos administrativos del aparato central para adquirir presencia en la promoción del crecimien to económico local y mayor autonomía política (Savitch, 1998: 249). El estudio del gobierno local se enmarca en las ciencias sociales y ha sido analizado desde las perspectivas económica, sociológica, política y de la administración pública. Desde el punto de vista económico, los gobiernos locales han alternado su participación entre la administración del crecimiento en periodos de prosperidad, y la promoción del crecimiento en etapas de depresión o rápido cambio tecnológico, como ocurre en la actualidad (Collinge, 1992: 73).

Así, los gobiernos locales han ido asumiendo un rol creciente en la promoción del crecimiento y, bajo un enfoque de planeación estratégica identifican las fortalezas y debilidades competitivas de la ciudad. Las segundas constituyen la misión del gobierno local y los resultados dependen de la efectividad de las autoridades y la cooperación 
entre los sectores público y privado. Esto es lo que Kresl menciona como determinantes estratégicos de la competitividad local.

Para concluir, a continuación presentaremos un ejercicio exploratorio de aplicación empírica de competitividad industrial en 30 ciudades del país.

\section{Competitividad industrial en 30 ciudades mexicanas, 1988-1998}

A partir de 1978 México es considerado un país preferentemente urbano porque concentra más de la mitad de su población en localidades urbanas. Para el 30 de junio de 1980 la población del país sumaba 66.9 millones, de los cuales 35.6 millones $(53.2 \%)$ residían en 227 localidades urbanas (con 15000 y más habitantes); en 1990 la población mexicana alcanzaba 81.7 millones y las 308 localidades urbanas albergaban 48.2 millones $(58.9 \%$ ), y en 2000 la población total al 30 de junio sumaba 98.1 millones y la población urbana 60.9 millones $(62.1 \%)$, con un sistema urbano conformado por 361 localidades, de las cuales siete tenían más de un millón de habitantes (Ciudad de México, Guadalajara, Monterrey, Puebla, Tijuana, Ciudad Juárez y León) y 38 habían rebasado sus límites político-administrativos o comandaban amplias relaciones funcionales hacia otros centros de población fuera de su municipio, conformando áreas metropolitanas.

En términos generales, los pasos a seguir para un estudio empírico sobre la competitividad local son tres: i) seleccionar un conjunto de ciudades y establecer un rango entre ellas en función de su competitividad, medida considerando su crecimiento económico comparativo; $i$ i) determinar las variables cuantitativas y cualitativas que expliquen la competitividad, es decir las ventajas competitivas, y obtener su medición estadística a partir de la información disponible, y iii) elaborar ejercicios estadísticos cuyos resultados permitan evaluar la competitividad local (Kresl, 1998: 711-714).

Con el objeto de avanzar en el conocimiento sobre la competitividad industrial de las principales ciudades del país entre 1988 y 1998 , en primer lugar se seleccionaron aquellas cuya población era de 250 mil y más habitantes en 1998, que eran 39 en total, y de ellas se seleccionaron las 30 con mayor generación de valor bruto de la producción en 1998. Los datos industriales se obtuvieron de los censos económicos de 1988 y 1998, homologándose los valores censales con los 
del sistema de cuentas nacionales. Dicha homologación consistió en reemplazar los valores absolutos censales de sueldos y salarios, valor bruto de la producción y valor agregado, o producto interno bruto, por los reportados en el sistema de cuentas nacionales, por considerar que los segundos son más certeros que los primeros. Asimismo, la información relativa a los establecimientos y al personal ocupado se mantuvo tal cual aparece en los censos. Cabe mencionar que 20 de las 30 ciudades seleccionadas son áreas metropolitanas, por lo que los datos industriales comprenden la agregación de los municipios conurbados. ${ }^{1}$

La competitividad no es un atributo que pueda ser medido directamente, sino que se debe adoptar algún indicador de la misma. En este caso se eligió el crecimiento del valor bruto de la producción (VBP) industrial entre 1988 y 1998, y la competitividad se estableció, en primer lugar, como el cambio en la participación absoluta de una ciudad en el VBP industrial nacional entre 1988 y $1998 .^{2}$ Para esos años el VBP industrial del país aumentó de 478400 a 869200 millones de pesos, lo cual significó un crecimiento relativo de $81.7 \%$. Por su parte, las 30 ciudades de estudio sumaron 401300 millones de pesos en 1988 y 686500 millones en 1998 y su participación en el total nacional mostró una contracción de 83.9 a $79 \%$. El cambio en la participación de las 30 ciudades presenta un proceso de desconcentración industrial hacia otras partes del territorio nacional. Incrementaron su participación absoluta 22 ciudades, lo que les confiere un carácter de competitivas, siendo la más significativa Guadalajara con un incremento de 2.3 puntos porcentuales, en tanto la Ciudad de México contó con la mayor pérdida participativa al retroceder 10.2 puntos porcentuales (véase el cuadro 1).

Un segundo indicador de competitividad utilizado se refiere a la contrastación del crecimiento relativo de la ciudad frente al observa-

' Para mayores detalles sobre el proceso de homologación de los datos de los censos económicos con los de las cuentas nacionales y la conformación de las 20 áreas me tropolitanas, véase Sobrino (2000: 244-258). En los datos industriales de las ciudades se omitieron las principales características de las actividades de refinación de petróleo y petroquímica básica. Todos los valores monetarios están expresados a precios constantes de 1993.

${ }^{2}$ Los indicadores que generalmente se utilizan para realizar estudios empíricos sobre la competiuividad son el empleo y el producto interno bruto. Aquí se seleccionó el valor bruto de la producción porque los datos censales muestran cambios en la participación por ciudades que resultan más creíbles con esta variable que los que se observan con el valor agregado. 
CUADRO 1

México: competitividad industrial de las principales ciudades, 1988-1998

\begin{tabular}{|c|c|c|c|c|c|c|c|c|c|c|c|c|}
\hline \multirow[b]{2}{*}{ Ciusdad } & \multicolumn{3}{|c|}{ VBP industriall } & \multicolumn{2}{|c|}{ Participación } & \multicolumn{2}{|c|}{ Cambio panticipativo } & \multicolumn{5}{|c|}{ Rango de competitividad ${ }^{2}$} \\
\hline & 1988 & 1998 & $\Delta$ & 1988 & 1993 & Absoluto & Relativo & $A$ & $B$ & $C$ & $D$ & $E$ \\
\hline México & 478384 & 869239 & 390855 & 100.00 & 100.00 & 0.00 & 0.00 & & & & & \\
\hline Ciudades & 401309 & 686535 & 285226 & 83.89 & 78.98 & -4.91 & -5.85 & & & & & \\
\hline AM Ciudad de México & 171826 & 223956 & 52130 & 35.92 & 25.76 & -10.15 & -28.27 & 30 & 26 & 1 & 26 & 24 \\
\hline AM de Monterrey & 46269 & 79203 & 32935 & 9.67 & 9.11 & -0.56 & -5.79 & 28 & 23 & 3 & 24 & 21 \\
\hline AM de Guadalajara & 29857 & 73965 & 44108 & 6.24 & 8.51 & 2.27 & 36.34 & 1 & 7 & 2 & 6 & 1 \\
\hline AM de Puebla & 15516 & 37209 & 21694 & 3.24 & 4.28 & 1.04 & 31.98 & 2 & 8 & 4 & 8 & 4 \\
\hline AM de Saltillo & 16524 & 31298 & 14775 & 3.45 & 3.60 & 0.15 & 4.25 & 12 & 20 & 6 & 22 & 15 \\
\hline AM de Toluca & 15484 & 31127 & 15649 & 3.24 & 3.58 & 0.34 & 10.64 & 8 & 16 & 5 & 23 & 12 \\
\hline AM de San Luis Potosí & 11074 & 20402 & 9329 & 2.31 & 2.35 & 0.03 & 1.40 & 20 & 21 & 10 & 21 & 19 \\
\hline AM de Querétaro & 9144 & 19774 & 10630 & 1.91 & 2.27 & 0.36 & 19.02 & 7 & 13 & 7 & 18 & 8 \\
\hline AM de Torreón & 6144 & 16518 & 10373 & 1.28 & 1.90 & 0.62 & 47.95 & 4 & 6 & 8 & 4 & 5 \\
\hline AM de Aguascalientes & 4379 & 14039 & 9661 & 0.92 & 1.62 & 0.70 & 76.46 & 3 & 2 & 9 & 2 & 2 \\
\hline Ciudad Juárez & 5914 & 13602 & 7688 & 1.24 & 1.56 & 0.83 & 26.58 & 9 & 10 & 11 & 15 & $\overrightarrow{9}$ \\
\hline AM de León & 5806 & 11656 & 5850 & 1.21 & 1.34 & 0.13 & 10.49 & 13 & 17 & 15 & 19 & 16 \\
\hline Hermosillo & 5329 & 11495 & 6166 & 1.11 & 1.32 & 0.21 & 18.70 & 10 & 14 & 14 & 13 & 11 \\
\hline AM de Monclova & 6919 & 11496 & 4516 & 1.45 & 1.32 & -0.13 & -9.04 & 23 & 24 & 16 & 20 & 25 \\
\hline AM de Tijuana & 8566 & 10621 & 7055 & 0.75 & 1.22 & 0.48 & 63.93 & 6 & 4 & 12 & 9 & 6 \\
\hline AM de Cuernavaca & 9179 & 10504 & 1325 & 1.92 & 1.21 & -0.71 & -37.02 & 29 & 30 & 27 & 30 & 30 \\
\hline Mexicali & 3006 & 10026 & 7020 & 0.63 & 1.15 & 0.53 & 83.57 & 5 & 1 & 13 & 1 & 3 \\
\hline Chihuahua & 7046 & 8891 & 1845 & 1.47 & 1.02 & -0.45 & -30.55 & 27 & 28 & 22 & 28 & 27 \\
\hline AM de Celaya & 4909 & 7022 & 2113 & 1.03 & 0.81 & -0.22 & -21.27 & 25 & 25 & 21 & 25 & 26 \\
\hline AM de Mérida & 3379 & 6624 & 3245 & 0.71 & 0.76 & 0.06 & 7.88 & 17 & 19 & 17 & 17 & 18 \\
\hline AM de Veracruz & 4608 & 5768 & 1160 & 0.96 & 0.66 & -0.30 & -31.11 & 26 & 29 & 28 & 29 & $\begin{array}{l}10 \\
29\end{array}$ \\
\hline AM de Taunpico & 3058 & 5591 & 2533 & 0.64 & 0.64 & 0.00 & 0.62 & 22 & 22 & 20 & 16 & 23 \\
\hline Matamoros & 2327 & 5259 & 2931 & 0.49 & 0.61 & 0.12 & 24.35 & 14 & 12 & 18 & 12 & 14 \\
\hline AM de Coarzacoalcos & 3294 & 4223 & 930 & 0.69 & 0.49 & -0.20 & -29.43 & 24 & 27 & 30 & 27 & 28 \\
\hline AM de Reynosa & 1264 & 3878 & 2614 & 0.26 & 0.45 & 0.18 & 68.88 & 11 & 3 & 19 & 5 & 7 \\
\hline Durango & 1224 & 2853 & 1629 & 0.26 & 0.33 & 0.07 & 28.30 & 16 & 9 & 23 & 7 & 13 \\
\hline Irapuato & 1426 & 2807 & 1381 & 0.30 & 0.32 & 0.02 & 8.30 & 21 & 18 & 25 & 14 & 22 \\
\hline Morelia & 1067 & 2421 & 1354 & 0.22 & 0.28 & 0.06 & 24.90 & 18 & 11 & 26 & 10 & 17 \\
\hline Mazatlán & 777 & 2218 & 1440 & 0.16 & 0.26 & 0.09 & 57.03 & 15 & 5 & 24 & 3 & 10 \\
\hline Culiacán & 996 & 2146 & 1151 & 0.21 & 0.25 & 0.04 & 18.64 & 19 & 15 & 29 & 11 & 20 \\
\hline
\end{tabular}

En millones de pesos de 1993

${ }^{2} \mathrm{~A}=$ cambio en la participación absoluta; $\mathrm{B}=$ cambio en la participación relativa; $\mathrm{C}=$ crecimiento absoluto; $\mathrm{D}=$ creciniento de la base económica, $\mathrm{y}$ $\mathrm{E}=$ competitividad ponderada.

Fuente: Cálculos elaborados con intormación de los censos industriales de 1988 y 1993 , y del Sistema de Cuentas Nacionales. 
do en el contexto nacional, es decir, su cambio participativo relativo. ${ }^{3}$ Mexicali fue la ciudad con el mayor crecimiento relativo; la tasa de crecimiento de Tampico fue la más cercana al total nacional, y Cuernavaca registró el menor dinamismo relativo de las 30 ciudades en cuestión (véase el cuadro 1 ).

Son estos indicadores de competitividad los que generalmente se utilizan en los ejercicios empíricos; sin embargo, se deben hacer algunas especificaciones adicionales considerando el patrón de concentración de la actividad industrial existente en el país y que en última instancia se refleja en el cambio absoluto. Entre 1988 y 1998 el vBP industrial del país aumentó 390900 millones de pesos, y la Ciudad de México fue la de mayor crecimiento con 52100 millones. Según los indicadores anteriores manejados, si bien ésta no fue una ciudad competitiva, su crecimiento absoluto superó 1.2 veces al de Guadalajara y 7.4 al de Mexicali, las dos ciudades con mayor competitividad por cambio participativo absoluto y relativo, respectivamente. Estas comparaciones ponen de manifiesto la necesidad de incorporar el crecimiento absoluto local dentro del análisis de competitividad industrial.

Por último, los destinos de la producción industrial de una ciudad son la atención de su mercado local y su venta fuera de ésta, que constituyen así su base económica o base exportadora (Goodall, 1977: 397-410). Si bien la expansión de la base exportadora debe corresponder no sólo al crecimiento económico local ocurrido, sino también al cambio en el comportamiento del mercado local y a la estructura productiva, al comparar la tasa de crecimiento del producto con la tasa de crecimiento poblacional 1988-1998 para cada ciudad se advierte que la ciudad de Mexicali registró el mayor estimador del crecimiento relativo de su base económica, seguida por Aguascalientes y Mazatlán, en tanto que el crecimiento relativo de la población fue mayor que el del VBP en Chihuahua, Veracruz y Cuernavaca (véase el cuadro 1 ).

El indicador de competitividad utilizado en el presente estudio se construyó con el promedio del rango de las cuatro variables; se le ha denominado competitividad ponderada, y su resultado aparece en la última columna del cuadro 1 . Con base en la información y en la metodología manejadas, la ciudad con mayor competitividad industrial en

${ }^{3}$ La fórmula utilizada fue $\left(\left(\mathrm{p}_{\mathrm{i} 1}-\mathrm{p}_{\mathrm{i} 0}\right) / \mathrm{p}_{\mathrm{i} 0}\right)^{*} 100$, en donde $\mathrm{p}_{\mathrm{i} 1}$ es la participación de la ciudad i en el vBP industrial nacional en 1998 y $\mathrm{P}_{\mathrm{i} 0}$ es la participación en 1988. 
el periodo 1988-1998 fue Guadalajara, seguida por Aguascalientes, Mexicali, Puebla y Torreón. Este indicador de competitividad se considera satisfactorio porque ubica en los últimos lugares a las ciudades no competitivas, pero por ejemplo no castiga a la Ciudad de México, que se ubicó en la posición 30 por cambio en la participación absoluta, y 24 en competitividad ponderada.

Cabe mencionar que el rango de competitividad se hubiera podido construir con valores estandarizados en vez de datos ordinales. Sin embargo, al ser muy elevado el coeficiente de variación de las variables utilizadas para la estimación de la competitividad, esto daría lugar a ponderaciones de sobrevaluación y subvaluación.

Una vez examinados el carácter y el ordenamiento competitivo de las 30 ciudades de estudio, lo que sigue es tratar de explorar las ventajas competitivas de tal desempeño. En el rubro anterior se mencionó que en la literatura no existe consenso sobre la determinación teórica e instrumental de las variables que expliquen la competitividad de una ciudad, por lo que se establece la siguiente propuesta: los factores de la competitividad local se componen por la interacción de tres tipos de ventajas competitivas: empresariales, territoriales y distributivas.

Las ventajas competitivas empresariales corresponden al funcionamiento, la organización in terna y la eficiencia microeconómica de las unidades productivas localizadas en la ciudad y se estudian con el comportamiento de la productividad, el uso potencial del capital humano, la intensidad del capital en el proceso productivo y el tamaño de los establecimientos.

Las ventajas competitivas territoriales se refieren a las condiciones externas que ofrecen los centros urbanos para la eficiencia microeconómica de las unidades productivas, las cuales se asocian a variables como tamaño de la ciudad, economías de aglomeración, características del mercado de trabajo, oferta de suelo para uso industrial, estructura económica local, oportunidades de acceso a actividades de apoyo y complementarias y desempeño de los gobiernos locales. Estas ventajas aluden a las condiciones de acceso de las unidades productivas a sus factores de la producción (tierra, trabajo y capital), o lo que las ciudades brindan para la oferta, así como el ambiente que prevalece para el desarrollo de los negocios y la participación del gobierno local en el fomento del crecimiento económico.

Por su parte, las ventajas competitivas distributivas se refieren a lo que las ciudades ofrecen para la distribución de los productos y que está relacionado con la posición geográfica, la existencia de condicio- 
nes generales de la circulación y el potencial de mercado; tiene que ver con las condiciones externas de las ciudades para incidir en el proceso productivo desde el punto de vista de la demanda.

En la clasificación propuesta de las ventajas competitivas locales se deben incluir dos consideraciones adicionales: por principio de cuentas estos determinantes se pueden analizar en forma estática o dinámica, cuantificando, por ejemplo, la situación de la productividad local en el tiempo $t_{0}$ y su cambio en el periodo de estudio. De manera adyacente, se pueden incluir indicadores que hablen del papel de la ciudad en el proceso de globalización y apertura comercial de las naciones, incorporando, por ejemplo, a las ventajas competitivas empresariales la presencia de empresas con capital extranjero; a las territoriales la existencia y participación de empresas exportadoras o maquiladoras en la estructura industrial local, y a las distributivas las interconexiones con el exterior a través de los pasajeros en vuelos internacionales, las llamadas telefónicas o la aplicación de modelos de potencial de mercado que eliminan fronteras entre países.

Para poner en operación la propuesta anterior de ventajas competitivas locales y explorar el desempeño competitivo de las 30 ciudades de estudio, se construyó una base de datos con los siguientes indicadores cuantitativos:

Ventajas competitivas empresariales: i) productividad parcial del trabajo (PPT); ii) remuneración promedio al personal ocupado (sueldos); iii) intensidad del capital, o relación capital-trabajo (capital); iv) tamaño promedio de los establecimientos (tamaño), y $v$ ) porcentaje del personal ocupado en la industria maquiladora de exportación respecto a la demanda ocupacional de la estructura productiva local $(I M E)$. Las tres primeras estiman la eficiencia microeconómica de los establecimientos manufactureros (véase Ballance, 1987: 217-226; González y Mariña, 1992; Roper, 1998) y la cuarta es una acotación de la concentración técnica (véase Utton, 1975: 21-37).

Ventajas competitivas territoriales: $i$ ) tamaño de la ciudad (población); ii) porcentaje de alumnos en instituciones de educación superior respecto a la población total (alumnos); iii) camas de hospital por cada 10000 habitantes (camas); iv) índice de marginación (calidad); v) porcentaje del personal ocupado en parques y ciudades industriales con relación a la demanda ocupacional (parques); vi) estructura económica local (IDE); vii) porcentaje del VBP de las actividades de servicios al productor respecto al VBP industrial (servicios); $i x$ ) monto del préstamo bancario per cápita (crédito), y x) ingreso público muni- 
cipal per cápita (ingresos). Los tres primeros vislumbran el grado de economias de urbanización (véase Begovic, 1991: 93-161; Richardson, 1986: 230-255); la ventaja competitiva calidad insinúa los niveles de bienestar social; parques indica el papel de los parques y ciudades industriales en la oferta de suelo y la organización intraurbana de usos del suelo; $D E$ evalúa el grado de especialización sectorial y la existencia de economías de localización (véase Robinson, 1998: 257-260); servicios y crédito estiman la existencia de servicios profesionales y financieros para el apoyo a la actividad industrial, e ingresos es un connotador de la eficiencia del gobierno local (véase Rosen, 1995: 29-35).

Ventajas competitivas distributivas: i) enlaces carreteros, o número de ciudades con las que la ciudad en cuestión se conecta de manera directa (enlaces); ii) distancia carretera promedio entre una ciudad y el resto de localidades de estudio (distancia); iii) potencial de mercado interno (potenciall); iv) potencial de mercado con Estados Unidos, ajustando el potencial anterior con la inclusión de los centroides económico-espaciales de los estados de California y Texas (potencial2), y $v$ ) porcentaje de pasajeros en vuelos internacionales respecto a la población total (pasajeros). El primero evalúa la estructura del sistema carretero del país (véase Peeters, Thiesse y Thomas, 1998: 355-357; Smith, 1975); la ventaja competitiva distancia acota la posición geográfica de la ciudad; potenciall y potencial2 señalan el área previsible de mercado para la demanda de los productos (véase Isard, 1973: 512-533), y pasajeros representa un estimador de los flujos con el extranjero.

Los valores de las 19 variables para las 30 ciudades de estudio se presentan en el cuadro Al del apéndice estadístico. Cada una se ordenó de mayor a menor y el rango obtenido por una ciudad significó su guarismo para ese factor competitivo (véase el cuadro A2 del apéndice estadístico). Todos los valores corresponden a 1988, por lo que representan una especie de radiografia cuantitativa de los indicadores de las ventajas competitivas existentes en ese momento. Asimismo, es indudable que estos indicadores no cubren todo el horizonte paradigmático de los conceptos de competitividad y ventajas competitivas, pero representan un intento de avance para examinarlos y ponerlos en operación.

Con la base de datos que se presenta en el cuadro $\mathrm{A} 2$ del apéndice estadístico, se corrió un modelo de regresión lineal múltiple considerando la competitividad ponderada como variable dependiente y las ventajas competitivas como independientes o explicativas. En un primer momento se corrió la regresión con las 19 variables explicativas, 
siendo éstas indicadoras de ventajas competitivas estáticas, pero se encontraron serios problemas de multicolinearidad porque la $\mathrm{R}^{2}$ era alta, las estadísticas $\mathbf{t}$ de los coeficientes de regresión $(\beta)$ bajas, y el factor de inflación de varianza (VIF) para todas las variables era mayor que 2 (véase Maddala, 1996: 147-347; y Pindyck y Rubinfeld, 2001: 91-101).

Por lo anterior se corrió un segundo ejercicio con el método hacia atrás (backward) que consiste en la eliminación iterativa de variables explicativas con la menor estadística t, con el propósito de maximizar $\mathrm{R}^{2}$ ajustada y que todos los coeficientes de regresión tuvieran una t con un nivel de significancia de 0.1 o menor. Este procedimiento arrojó un modelo explicativo con ocho variables, pero aún mostraba problemas de multicolinearidad, por lo que manualmente se eliminaron dos variables. ${ }^{4}$

Los resultados del modelo se presentan en el cuadro 2 y con ellos se concluye que el juego de la competitividad industrial en México entre sus principales ciudades en el periodo 1988-1998 se caracterizó por que la mayor competitividad ocurrió en aquellas ciudades que en 1988 tenían los menores niveles de eficiencia microeconómica de sus unidades productivas, como muestra el signo negativo del coeficiente de regresión de la variable capital y su elevada correlación con las variables PPT y sueldos; combinado con el efecto de tres ventajas competitivas territoriales, una, camas, que alude a la relación positiva entre economías de urbanización y competitividad; otra que establece que la mayor competitividad ocurrió en ciudades con una estructura productiva diversificada, que se muestra por el coeficiente negativo de la variable $I D E$, y una más que insinúa la nula relación entre el desempeño industrial y los servicios profesionales de apoyo a la producción, lo que establece el signo negativo de la variable servicios.

Las variables explicativas del ejercicio exploratorio se complementan con dos indicadores de ventajas competitivas distributivas, siendo éstas enlaces y distancia, cuyos coeficientes permiten inferir que la posición geográfica hacia la parte central del país y la estructura del sistema carretero coadyuvaron a la competitividad industrial de las ciudades (véase el cuadro 2).

${ }^{4} \mathrm{El}$ modelo de regresión con las seis variables explicativas obtuvo una $\mathrm{R}^{2}$ ajustada de 0.299 ; la prueba Durbin-Watson 1.727 que no indica autocorrelación serial; todos los VIF fueron menores a 1.7 y el índice de condición fue11.608, por lo que no existe multicolinearidad, y la prueba RESET mostró no heterocedasticidad. 
CUADRO 2

Ciudades de estudio: ventajas competitivas estáticas del desempeño industrial, 1988-1998

\begin{tabular}{lrrrr}
\hline Modelo & \multicolumn{1}{c}{$\beta$} & \multicolumn{1}{c}{$\boldsymbol{s}$} & sig. & $V I F$ \\
\hline Constante & 29.043 & 5.006 & 0.000 & \\
Capital & -0.589 & -3.229 & 0.004 & 1.379 \\
Camas & 0.220 & 1.095 & 0.285 & 1.669 \\
DE & -0.175 & -0.938 & 0.358 & 1.449 \\
Servicios & -0.405 & -2.016 & 0.056 & 1.671 \\
Enlaces & 0.317 & 1.525 & 0.141 & 1.632 \\
Distancia & -0.182 & -1.022 & 0.317 & 1.310 \\
\hline
\end{tabular}

Fuente: Ejercicio de regresión con los valores del cuadro A2.

Estos resultados permiten suponer que la competitividad alcanzada por las ciudades estuvo determinada preferentemente por ventajas competitivas territoriales, como el aprovechamiento de las economías de urbanización y la existencia de una estructura productiva diversificada, así como la posición geográfica de la ciudad y el esquema carretero que permitían ventajas competitivas distributivas. Llama la atención el poco efecto de las ventajas competitivas empresariales.

Con objeto de conocer el papel de las ventajas competitivas dinámicas en el crecimiento industrial se corrió otro ejercicio de regresión lineal múltiple utilizando nuevamente el rango de la competitividad ponderada como variable dependiente, y como independientes las siguientes: i) cambio en la productividad parcial del trabajo, 1988-1998 (PPT) ; ii) cambio en la remuneración promedio al personal ocupado, 1988-1993 (sueldos); iii) cambio en la intensidad del capital, 1988-1993 (capital); iv) tasa de crecimiento promedio anual de la población, 1990-2000 (población); v) cambio en el porcentaje de alumnos en instituciones de educación superior respecto a la población total, 19881998 (alumnos); vi) decremento en el índice de marginación local, 1990-1995 (calidad); vii) aumento en el porcentaje del personal ocupado en empresas ubicadas en parques y ciudades industriales respecto al personal ocupado industrial total, 1988-1998 (parques); viii) aumento en los niveles de concentración sectorial de la estructura productiva, 1988-1993 (DE); ix) aumento en el porcentaje del personal ocupado en empresas maquiladoras con respecto al personal ocupado industrial total, 1988-1998 (IME); $x$ ) cambio en el monto del cré- 
dito per cápita, 1988-1993 (crédito); xi) cambio en el ingreso público municipal per cápita, 1988-1998 (ingresos), y xii) componente diferencial relativo de un ejercicio de cambio y participación para los grupos industriales que mostraron el mayor dinamismo exportador en el contexto nacional, 1988-1993 (exporta) (véase Blair, 1995: 145-149; Dussel, 1995: 460-469).

Los valores de estas variables exploratorias de ventajas competitivas dinámicas aparecen en el cuadro A3 y su ordenamiento en el cuadro A4 del apéndice estadístico.

Nuevamente el modelo con las 11 variables presentaba problemas de multicolinearidad, por lo que se aplicó un método backward que arrojó seis variables explicativas (véase el cuadro 3) ${ }^{5}$

CUADRO 3

Ciudades de estudio: ventajas competitivas dinámicas del desempeño industrial, 1988-1998

\begin{tabular}{lrrrl}
\hline Modelo & \multicolumn{1}{c}{$\beta$} & \multicolumn{1}{c}{$t$} & sig. & VIF \\
\hline Constante & -0.571 & -0.132 & 0.896 & \\
PPT & 0.327 & 2.103 & 0.046 & 1.113 \\
Parques & 0.149 & 0.861 & 0.398 & 1.372 \\
DE & -0.159 & -0.912 & 0.371 & 1.395 \\
Ingresos & 0.164 & 0.977 & 0.338 & 1.304 \\
Exporta & 0.555 & 3.582 & 0.002 & 1.106 \\
\hline
\end{tabular}

Fuente: Ejercicio de regresión con los valores del cuadro A4.

El resultado del ejercicio estadístico de ventajas competitivas dinámicas es más halagüeño que el de ventajas competitivas estáticas, pues ratifica la visión de Porter sobre el concepto de ventajas competitivas como factores dinámicos que se desarrollan en el tiempo, y permite proponer que la competitividad industrial entre las principa-

${ }^{3} \mathrm{La} \mathrm{R}^{2}$ ajustada se ubicó en 0.370 , la prueba Durbin-Watson fue 2.031 , los VIF menores a 1.4 , el índice de condición 8.732 y la prueba RESET aceptó la hipótesis nula de $\beta_{i}=0$. Por ello, este madelo tampoco presenta autocorrelación serial, multicolinearidad ni heterocedasticidad. 
les ciudades del país entre 1988 y 1998 se susten tó en el incremento en la productividad relativa del factor trabajo y en la orientación de la ciudad hacia los mercados de exportación; de manera adicional, las ciudades con mayor competitividad no mostraron una tendencia a la concentración sectorial de su estructura productiva (que hablaría de la conformación de clusters de actividades) sino por el contrario hacia una diversificación de su planta productiva, además que escenificaron un crecimiento significativo de sus parques y ciudades industriales y gobiernos locales con mayor eficiencia en la recaudación de ingresos municipales.

Si bien existen limitaciones instrumentales, el ejercicio exploratorio permite concluir que la competitividad local en México se sustenta más en fuerzas dinámicas y menos en estáticas de ventajas competitivas, siendo que las ventajas empresariales se enfocan hacia un uso más eficiente de la mano de obra, que no del capital humano; las territoriales hacia la oferta de suelo en parques y ciudades industriales, una estructura productiva diversificada y eficiente administración de los gobiernos municipales, y las distributivas hacia condiciones favorables para el acceso a los mercados de exportación.

\section{Reflexiones finales}

El proceso de globalización ha motivado, entre otras cosas, la reestructuración de la teoría del comercio internacional, incorporando nuevas vertientes explicativas como los conceptos de competitividad y ventajas competitivas. La definición del primero es clara, mientras que para el segundo existe cierto acuerdo sobre los determinantes de la competitividad nacional, aunque algunos enfoques enfatizan más el papel del gobierno central y la adopción de políticas públicas, en tanto que otros dan prioridad al comportamiento microeconómico de las unidades productivas.

Desde la década de los ochenta del pasado siglo xx, el país ha adoptado una política económica de apertura comercial y su desempeño competitivo ha sido exitoso si se mide con el incremento de sus exportaciones. Sin embargo, los diversos ejercicios de cuantificación de ventajas competitivas lo ubican en una posición más bien vulnerable, por lo que la competitividad nacional se ha sustentado en fuentes estáticas relacionadas con diferenciales en salarios relativos, sin avanzar en la creación y aprovechamiento de fuentes dinámicas de venta- 
jas cumpetitivas. La remuneración promedio al personal ocupado en la industria manufacturera del país en 1988 fue de 22371 pesos (a precios constantes de 1993); aumentó a 26634 en 1993, ante un crecimiento moderado de la economía nacional, para caer a 22131 en 1998 como consecuencia de la crisis financiera de finales de 1994 y la puesta en marcha del Tratado de Libre Comercio con Estados Unidos y Canadá. Por lo anterior el país no ha sido capaz de delinear un crecimiento endógeno, es decir, de crear las condiciones internas para un futuro crecimiento sustentable.

Si bien la literatura sobre la competitividad local y los factores de la misma es abundante, no existe aún consenso sobre la determinación de las ventajas competitivas, lo que dio pauta para proponer en este artículo una clasificación de ellas: empresariales, territoriales y distributivas.

En los postulados de la teoría económica espacial se acepta que el crecimiento de un país es similar al experimentado por sus principales ciudades, debido a la elevada proporción de la población y las actividades económicas que concentran (Goodall, 1977: 45). Si este postulado se aplicara al concepto de competitividad, entonces los determinantes de la compétitividad nacional que no están relacionados con elementos de política macroeconómica (tasa de cambio, salarios relativos o aranceles) deberían estar presentes en sus principales núcleos urbanos. Por tanto, la competitividad de un país está en función del desempeño microeconómico de las unidades productivas, de la instrumentación de políticas públicas para promover el crecimiento económico y de la existencia y evolución de las ventajas territoriales y distributivas que ofrecen las ciudades para el desarrollo de las actividades económicas.

El propósito del ejercicio empírico presentado ha sido proponer variables cuantitativas para medir la competitividad industrial de las principales ciudades del país en el periodo 1988-1998, y explorar variables explicativas de tal comportamiento a partir de la identificación de ciertas variables cuantitativas que se ajustaran lo más posible a la clasificación conceptual de las ventajas competitivas de las ciudades. Si bien los resultados arrojan conclusiones preliminares debido a la probable imposibilidad de cuantificar adecuadamente el indicador de competitividad local y sus variables explicativas, en cambio ofrecen un punto de partida para proseguir con estudios empíricos sobre el tema en México, despejar el camino a futuros trabajos y seguir reflexionando sobre los conceptos y la instrumentación operativa de la competitividad de las ciudades. 
Estudios empíricos realizados para cuantificar las ventajas competitivas de los países ubican a México en una magra posición, y los resultados de los modelos de regresión realizados para 30 ciudades del país ratifican la no creación y aprovechamiento de ventajas competitivas que propone la teoría. Sin embargo, el segundo modelo (determinantes dinámicos) ofrece una esperanza porque el desempeño competitivo de las ciudades se explicó por un incremento en la productividad parcial del trabajo, la creación de parques industriales y un mejoramiento en la eficiencia administrativa de los gobiernos locales.

La literatura y algunos ejercicios empíricos han mostrado la relación entre ciudad competitiva y región competitiva, concluyendo que cuando una ciudad es mucho más competitiva que su región, entonces la economía local depende más de su base económica y menos del crecimiento local. La relación ciudad competitiva-región no competitiva indicaría un proceso de polarización territorial (delinking) y la inexistencia de efectos difusores.

El autor del presente artículo realizó un estudio sobre el cambio y la participación industrial por entidad federativa en el periodo 1982-2000 utilizando como fuente de información el producto interno bruto registrado en el sistema de cuen tas nacionales. Al comparar los resultados de ese documento con los presentados en éste sobre competitividad industrial local utilizando como variable el valor bruto de la producción de los censos industriales, se concluye la relación general existente entre ciudad competitiva y competitividad de la entidad federativa a la que pertenece. Las entidades federativas con el mejor desempeño industrial fueron: Aguascalientes, Baja California, Coahuila, Puebla, Querétaro y Tamaulipas, en todas las cuales se ubica al menos una ciudad entre las 30 más importantes del país por tamaño de población y generación de riqueza industrial; ciudades que en su gran mayoría ocuparon los primeros rangos de competitividad. Asimismo, los estados de Chihuahua, Durango, Guanajuato, México, Michoacán, Sonora y Yucatán mostraron un crecimiento intermedio y sus principales ciudades obtuvieron rangos situados a media tabla de competitividad. Por último, las entidades con menor crecimiento industrial fueron Campeche, Chiapas, Nayarit, Oaxaca, Veracruz y la Zona Metropolitana de la Ciudad de México, de las cuales las cuatro primeras no cuentan con alguna ciudad de entre las 30 más importantes del país, en tanto que las zonas urbanas de las dos últimas se posicionaron entre las de menor competitividad. 
Sin embargo existen inconsistencias en los datos de ambas fuentes de información, ya que Jalisco y Sinaloa se consideran entidades con un escaso desempeño industrial, pero sus principales ciudades obtuvieron significativos niveles competitivos, mientras en el polo opuesto aparecen Morelos y Nuevo León como entidades con un crecimiento industrial significativo, pero reducida competitividad de su núcleo urbano principal.

A pesar de estas inconsistencias, que muestran la necesidad de que futuros trabajos reflexionen sobre la comparación de ambas fuentes de información, estos resultados dan indicios, para el caso mexicano, de la estrecha relación entre el desempeño económico de una entidad federativa y el comportamiento competitivo de su principal o principales núcleos urbanos.

Algunas aportaciones al tema de competitividad urbana enfatizan el papel de los gobiernos locales para la promoción del crecimiento económico. Dicha intervención significa crear las condiciones propicias para el aprovechamiento de las ventajas competitivas territoriales, quedando el gobierno central como responsable para coadyuvar al fomento de las ventajas competitivas empresariales y consolidar las ventajas competitivas distributivas.

Si se toman como punto de partida los resultados de los modelos de regresión realizados, entonces la promoción del crecimiento económico por parte de los gobiernos locales en México se debería enfocar hacia la consolidación de sus economías de urbanización, el ordenamiento de usos del suelo, particularmente el industrial, y un claro establecimiento de la opción para su desarrollo mediante: $i$ ) la expansión cuantitativa de su estructura productiva, si la ciudad muestra un crecimiento económico significativo, o ii) la reestructuración cualitativa de sus actividades, si no ha mostrado condiciones de competitividad. Ambas opciones requieren cambios institucionales e inversiones, estrategias de competitividad en donde se podría incorporar además la cooperación entre ciudades (Kresl, 1998: 695-696).

Un sistema urbano eficiente y competitivo propicia beneficios para la economía nacional, lievando a la competitividad urbana a ser algo más que un simple juego de suma cero. Para lograrlo es necesario instrumentar políticas territoriales bajo una óptica de coordinación entre los niveles central y local.

Por último, es necesario recordar que la competitividad económica y la calidad de vida no deben ser dos circuitos independientes, sino elementos interrelacionados de una pirámide que se sustenta en la 
eficiencia microeconómica y se traduce en mejores condiciones de vida para la población. En los ejercicios de regresión realizados se utilizó la variable "índice de marginación por localidad" elaborado por el Conapo para 1990 y 1995, y se concluyó que la competitividad de las principales ciudades del país no se relacionó con su calidad de vida, aspecto que se comprueba con la no correlación entre ambas variables, y su eliminación en el método hacia atrás de regresión múltiple cuando se incorporó con las variables explicativas. Asimismo, el incremento en la calidad de vida tampoco se relacionó con la competitividad urbana, tanto en su asociación simple como en su integración al modelo de regresión múltiple.

Por tanto, la competitividad industrial no fue acompañada por un incremento en el bienestar social. Según los postulados teóricos de las ventajas competitivas, las ciudades escenifican los circuitos interrelacionados de crecimiento económico y desarrollo social, pero lo anterior no fue palpable en las principales ciudades del país. El desempeño industrial arroja mayor riqueza en las economías urbanas y valor agregado en el contexto nacional, por lo que no es un juego de suma cero, pero los mecanismos existentes para la provisión y prestación de servicios públicos corresponden a una lógica diferente y regulada por la eficiencia de los gobiernos locales, las relaciones intergubernamentales y el sistema financiero del país. Unir los circuitos de competitividad local y calidad de vida constiturye uno de los rubros fundamentales en la agenda de los gobiernos locales de México en el inicio de este tercer milenio. 


\begin{tabular}{|c|c|c|c|c|c|c|c|c|c|}
\hline \multicolumn{10}{|c|}{$\begin{array}{l}\text { Apéndice estadístico } \\
\text { CUADRO Al } \\
\text { Indicadores de ventajas competitivas estáticas }\end{array}$} \\
\hline Ciudad & $P P T$ & Sueldos & Capital & Tamaño & Población & Alumnos & Camas & Calidad & Parques \\
\hline México & 190371 & 22371 & 117734 & 18.1 & 78532402 & 1.6 & 6.8 & 2.018 & 12.5 \\
\hline Cilıdades & 202570 & 23452 & 113209 & 26.6 & 31877266 & 2.9 & 9.5 & 2.187 & 12.4 \\
\hline 1. AM Ciudad de México & 212354 & 25063 & 94033 & 25.6 & 14184841 & 2.3 & 7.9 & 2.270 & 0.2 \\
\hline 2. AM de Monterrey & 241542 & 26401 & 147124 & 36.7 & 2388604 & 3.1 & 10.7 & 2.285 & 1.1 \\
\hline 3. AM de Guadalajara & 200930 & 20228 & 98106 & 21.6 & 2722650 & 3.6 & 10.6 & 2209 & 2.9 \\
\hline 4. AM de Puebla & 198272 & 24638 & 178101 & 16.0 & 1229964 & 6.7 & 12.7 & 2.253 & 14.1 \\
\hline 5. AM de Saltillo & 498868 & 24470 & 291309 & 36.1 & 408435 & 3.2 & 8.6 & 2.247 & 1.9 \\
\hline 6. AM de Toluca & 318252 & 29069 & 245445 & 37.3 & 580809 & 4.6 & 9.2 & 2.294 & 3.9 \\
\hline 7. AM de San Luis Potosí & 289251 & 21286 & 171259 & 23.8 & 569368 & 3.6 & 8.6 & 2.278 & 31.7 \\
\hline 8. AM de Querétaro & 266178 & 31087 & 216767 & 43.0 & 380924 & 3.0 & 12.9 & 2.291 & 25.6 \\
\hline 9. AM de Torreón & 145489 & 14849 & 53521 & 25.4 & 653596 & 3.3 & 10.3 & 2.255 & 38.5 \\
\hline 10. AM de Aguascalientes & 131980 & 15748 & 82841 & 24.8 & 430495 & 1.9 & 8.1 & 2.298 & 47.8 \\
\hline 11. Ciudad Juárez & 54673 & 19932 & 19364 & 86.3 & 740002 & 1.6 & 5.9 & 2.194 & 44.1 \\
\hline 12. AM de León & 97451 & 11717 & 35215 & 18.3 & 798391 & 0.8 & 13.6 & 2.138 & 2.7 \\
\hline 13. Hermosillo & 471881 & 26997 & 164345 & 17.2 & 384831 & 6.6 & 15.8 & 2.147 & 52.7 \\
\hline 14. AM de Monclova & 239795 & 44660 & 507935 & 76.1 & 251235 & 1.1 & 10.6 & 2.181 & 0.0 \\
\hline 15. AM de Tijuana & 85159 & 18631 & 22794 & 40.7 & 667711 & 1.3 & 8.0 & 2.062 & 26.5 \\
\hline 16. AM de Cuernavaca & 409985 & 31169 & 150099 & 23.8 & 398400 & 2.2 & 8.2 & 2.201 & 55.0 \\
\hline
\end{tabular}




\begin{tabular}{|c|c|c|c|c|c|c|c|c|c|}
\hline 17. Mexicali & 122379 & 20428 & 40343 & 38.4 & 419714 & 2.4 & 15.3 & 2.212 & 30.3 \\
\hline 18. Chihuahua & 166418 & 21308 & 89569 & 42.9 & 490571 & 3.8 & 8.2 & 2.313 & 83.3 \\
\hline 19. AM de Celaya & 263471 & 22467 & 128113 & 24.1 & 281744 & 1.6 & 7.4 & 2.166 & 13.2 \\
\hline 20. AM de Mérida & 143340 & 13728 & 79074 & 14.7 & 572728 & 2.4 & 13.5 & 2.175 & 16.0 \\
\hline 21. AM de Veracruz & 259235 & 26971 & 463808 & 22.3 & 413812 & 5.2 & 19.4 & 2.171 & 16.2 \\
\hline 22. AM de Tampico & 300837 & 24750 & 175530 & 11.9 & 486979 & 5.8 & 11.1 & 2.259 & 2.6 \\
\hline 23. Matamoros & 64740 & 22009 & 29026 & 91.2 & 250599 & 1.5 & 9.4 & 2.006 & 31.7 \\
\hline 24. AM de Coatzacoalcos & 618033 & 55580 & 406915 & 19.7 & 232834 & 1.2 & 6.2 & 2.038 & 19.8 \\
\hline 25. AM de Reynosa & 51691 & 16876 & 11488 & 47.9 & 316508 & 1.1 & 6.1 & 2.069 & 83.3 \\
\hline 26. Durango & 87569 & 11966 & 64895 & 18.0 & 330321 & 3.0 & 11.9 & 2.227 & 25.3 \\
\hline 27. Irapuato & 128838 & 12916 & 65549 & 18.9 & 245332 & 0.2 & 8.4 & 2.076 & 11.0 \\
\hline 28. Morelia & 110577 & 11668 & 81240 & 7.9 & 402092 & 7.5 & 16.7 & 2.156 & 9.3 \\
\hline 29. Mazatlán & 128270 & 16973 & 45770 & 13.6 & 250471 & 3.3 & 10.9 & 2.048 & 22.2 \\
\hline 30. Culiacán & 124053 & 13024 & 77302 & 11.2 & 393304 & 9.1 & 11.6 & 2.103 & 0.5 \\
\hline
\end{tabular}




\begin{tabular}{|c|c|c|c|c|c|c|c|c|c|c|}
\hline & DEE & $I M E$ & Servicios & Crédito & Ingresos & Enlaces & Distancia & Potenciall & Potencial2 & Pasajeros \\
\hline México & 0.041 & 21.5 & 14.6 & 476 & 286 & & & & & 3.2 \\
\hline Ciudades & 0.056 & 12.2 & 18.9 & 1033 & 512 & 3 & 1161 & 1496 & 1764 & 15.5 \\
\hline 1. AM Ciudad de México & 0.029 & 0.1 & 28.8 & 1644 & 962 & 6 & 867 & 14730 & 14928 & 23.0 \\
\hline 2. AM de Monterrey & 0.047 & 3.0 & 19.9 & 1124 & 167 & 5 & 990 & 3618 & 3958 & 9.8 \\
\hline 3. AM de Guadalajara & 0.105 & 4.2 & 9.7 & 584 & 140 & 5 & 901 & 3207 & 3437 & 30.6 \\
\hline 4. AM de Puebla & 0.102 & 0.0 & 7.6 & 542 & 70 & 4 & 927 & 1771 & 1963 & 0.0 \\
\hline 5. AM de Saltillo & 0.350 & 9.6 & 6.2 & 495 & 128 & 5 & 954 & 1330 & 1652 & 0.0 \\
\hline 6. AM de Toluca & 0.078 & 0.0 & 1.9 & 285 & 180 & 4 & 870 & 2986 & 3187 & 0.4 \\
\hline 7. AM de San Luis Potosí & í 0.058 & 0.0 & 4.0 & 460 & 108 & 5 & 822 & 1094 & 1335 & 0.0 \\
\hline 8. AM de Querétaro & 0.130 & 0.0 & 6.3 & 302 & 130 & 3 & 804 & 1287 & 1506 & 0.0 \\
\hline 9. AM de Torreón & 0.189 & 8.4 & 13.7 & 552 & 189 & 4 & 1030 & 948 & 1236 & 0.4 \\
\hline 10. AM de Aguascaliente & 0.104 & 0.0 & 7.6 & 779 & 132 & $\mathbf{5}$ & 889 & 900 & 1138 & 0.0 \\
\hline 11. Ciudad Juárez & 0.220 & 80.6 & 8.8 & 276 & 195 & 2 & 1634 & 934 & 1202 & 0.7 \\
\hline 12. AM de León & 0.463 & 0.0 & 9.6 & 325 & 117 & 2 & 829 & 1012 & 1237 & 0.0 \\
\hline 13. Hermosillo & 0.207 & 37.8 & 9.6 & 376 & 169 & 4 & 1669 & 586 & 918 & 7.7 \\
\hline 14. AM de Monclova & 0.749 & 0.0 & 23.2 & 229 & 103 & 3 & 1120 & 499 & 789 & 0.0 \\
\hline 15. AM de Tijuana & 0.136 & 77.0 & 13.4 & 258 & 234 & 2 & 2443 & 697 & 1461 & 0.7 \\
\hline 16. AM de Cuernavaca & 0.414 & 0.0 & 3.8 & 127 & 92 & 2 & 947 & 2031 & 2222 & 0.0 \\
\hline 17. Mexicali & 0.044 & 67.4 & 14.7 & 646 & 438 & 3 & 2275 & 404 & 980 & 4.8 \\
\hline 18. Chihuahua & 0.154 & 70.2 & 9.1 & 581 & 146 & 4 & 1309 & 623 & 903 & 3.6 \\
\hline
\end{tabular}




\begin{tabular}{lrrrrrrrrrr} 
19. AM de Celaya & 0.191 & 0.0 & 11.9 & 237 & 119 & 2 & 811 & 932 & 1150 & 0.0 \\
20. AM de Mérida & 0.147 & 0.0 & 18.0 & 349 & 98 & 1 & 2071 & 451 & 581 & 18.2 \\
21. AM de Veracruz & 0.151 & 0.0 & 29.0 & 400 & 156 & 4 & 1084 & 561 & 747 & 0.4 \\
22. AM de Tampico & 0.322 & 0.0 & 10.0 & 335 & 128 & 5 & 943 & 577 & 807 & 1.7 \\
23. Matamoros & 0.135 & 90.3 & 6.2 & 229 & 155 & 2 & 1125 & 591 & 891 & 2.6 \\
24. AM de Coatzacoalcos & 0.797 & 0.0 & 8.8 & 415 & 238 & 2 & 1330 & 511 & 635 & 0.0 \\
25. AM de Reynosa & 0.215 & 80.9 & 9.6 & 232 & 84 & 3 & 1095 & 489 & 815 & 2.6 \\
26. Durango & 0.469 & 0.0 & 24.1 & 174 & 77 & 4 & 986 & 301 & 556 & 0.0 \\
27. Irapuato & 0.499 & 0.0 & 9.9 & 328 & 154 & 3 & 854 & 658 & 878 & 0.0 \\
28. Morelia & 0.084 & 0.0 & 14.4 & 194 & 59 & 4 & 871 & 603 & 812 & 0.0 \\
29. Mazatlán & 0.296 & 0.0 & 20.9 & 872 & 227 & 3 & 1119 & 273 & 485 & 160.7 \\
30. Culiacán & 0.498 & 0.0 & 25.7 & 1291 & 203 & 2 & 1269 & 265 & 521 & 0.0 \\
\hline
\end{tabular}

Fuente: Cálculos elaborados con información de INEGI, Censos de población y vivienda 1990 y 2000, Censos industrial y de servicios, 1989, 1994 y 1999, Finanzas públicas municipales, 1988-1998, Sistema de Cuentas Nacionales de México y página web, Banco de Información Económica; Consejo Nacional de Población, Índice de Marginación por Localidad, 1990-1995; Poder Ejecutivo Federal, Sexto in forme de gobierno, 1994 y 2000, anexo; Sistema Mexicano de Promoción de Parques Industriales, página web; y Mercamétrica Ediciones, Mercamétrica de 80 ciudades mexicanas, 1990 y 1995. 
CUADRO A2

Ordenamiento de los indicadores de ventajas competitivas estáticas por ciudad

\begin{tabular}{|c|c|c|c|c|c|c|c|c|c|c|}
\hline Ciudad & Competit. & $P P T$ & Sueldos & Capital & Tamaño & Población & Alumnos & Camas & Calidad & Parques \\
\hline 1. AM Ciudad de México & 24 & 13 & 9 & 15 & 12 & 1 & 19 & 5 & 7 & 29 \\
\hline 2. AM de Monterrey & 21 & 11 & 8 & 12 & 10 & 3 & 14 & 14 & 5 & 27 \\
\hline 3. AM de Guadalajara & 1 & 14 & 18 & 14 & 19 & 2 & 9 & 15 & 14 & 23 \\
\hline 4. AM de Puebla & 4 & 15 & 11 & 7 & 25 & 4 & 3 & 9 & 10 & 18 \\
\hline 5. AM de Saltillo & 15 & 2 & 12 & 4 & 11 & 17 & 13 & 20 & 11 & 26 \\
\hline 6. AM de Toluca & 12 & 5 & 5 & 5 & 9 & 9 & 7 & 19 & 3 & 22 \\
\hline 7. AM de San Luis Potosí & 19 & 7 & 16 & 9 & 16 & 11 & 10 & 21 & 6 & 8 \\
\hline 8. AM de Querétaro & 8 & 8 & 4 & 6 & 5 & 22 & 16 & 8 & 4 & 12 \\
\hline 9. AM de Torreón & 5 & 17 & 24 & 23 & 13 & 8 & 12 & 17 & 9 & 7 \\
\hline 10. AM de Aguascalientes & 2 & 19 & 23 & 17 & 14 & 14 & 21 & 25 & 2 & 5 \\
\hline 11. Ciudad Juárez & 9 & 29 & 19 & 29 & 2 & 6 & 22 & 30 & 16 & 6 \\
\hline 12. AM de León & 16 & 25 & 29 & 26 & 22 & 5 & 29 & 6 & 23 & 24 \\
\hline 13. Hermosillo & 11 & 3 & 6 & 10 & 24 & 21 & 4 & 3 & 22 & 4 \\
\hline 14. AM de Monclova & 25 & 12 & 2 & 1 & 3 & 26 & 27 & 16 & 17 & 30 \\
\hline 15. AM de Tijuana & 6 & 27 & 20 & 28 & 7 & 7 & 25 & 26 & 27 & 11 \\
\hline 16. AM de Cuernavaca & 30 & 4 & 3 & 11 & 17 & 19 & 20 & 23 & 15 & 3 \\
\hline 17. Mexicali & 3 & 23 & 17 & 25 & 8 & 15 & 18 & 4 & 13 & 10 \\
\hline 18. Chihuahua & 27 & 16 & 15 & 16 & 6 & 12 & 8 & 24 & 1 & 2 \\
\hline 19. AM de Celaya & 26 & 9 & 13 & 13 & 15 & 25 & 23 & 27 & 20 & 19 \\
\hline
\end{tabular}




\begin{tabular}{lrrrrrrrrrr} 
20. AM de Mérida & 18 & 18 & 25 & 19 & 26 & 10 & 17 & 7 & 18 & 17 \\
21. AM de Veracruz & 29 & 10 & 7 & 2 & 18 & 16 & 6 & 1 & 19 & 16 \\
22. AM de Tampico & 23 & 6 & 10 & 8 & 28 & 13 & 5 & 12 & 8 & 25 \\
23. Matamoros & 14 & 28 & 14 & 27 & 1 & 27 & 24 & 18 & 30 & 9 \\
24. AM de Coatzacoalcos & 28 & 1 & 1 & 3 & 20 & 30 & 26 & 28 & 29 & 15 \\
25. AM de Reynosa & 7 & 30 & 22 & 30 & 4 & 24 & 28 & 29 & 26 & 1 \\
26. Durango & 13 & 26 & 28 & 22 & 23 & 23 & 15 & 10 & 12 & 13 \\
27. Irapuato & 22 & 20 & 27 & 21 & 21 & 29 & 30 & 22 & 25 & 20 \\
28. Morelia & 17 & 24 & 30 & 18 & 30 & 18 & 2 & 2 & 21 & 21 \\
29. Mazatlán & 10 & 21 & 21 & 24 & 27 & 28 & 11 & 13 & 28 & 14 \\
30. Culiacán & 20 & 22 & 26 & 20 & 29 & 20 & 1 & 11 & 24 & 28 \\
\hline
\end{tabular}


IDE IME Servicios Crédito Ingresos Enlaces Distancia Potenciall Potencial2 Pasajeros

$\begin{array}{lrrrrrrrrrr}\text { 1. AM Ciudad de México } & 30 & 12 & 2 & 1 & 1 & 1 & 6 & 1 & 1 & 3 \\ \text { 2. AM de Monterrey } & 28 & 11 & 7 & 3 & 11 & 2 & 16 & 2 & 2 & 6 \\ \text { 3. AM de Guadalajara } & 22 & 10 & 16 & 7 & 16 & 2 & 10 & 3 & 3 & 2 \\ \text { 4. AM de Puebla } & 24 & 13 & 23 & 10 & 29 & 8 & 11 & 6 & 6 & 23 \\ \text { 5. AM de Saltillo } & 8 & 8 & 26 & 11 & 19 & 2 & 14 & 7 & 7 & 24 \\ \text { 6. AM de Toluca } & 26 & 13 & 30 & 21 & 9 & 8 & 7 & 4 & 4 & 22 \\ \text { 7. AM de Sán Luis Potosí } & 27 & 13 & 28 & 12 & 23 & 2 & 3 & 9 & 10 & 24 \\ \text { 8. AM de Querétaro } & 21 & 13 & 25 & 20 & 18 & 16 & 1 & 8 & 8 & 24 \\ \text { 9. AM de Torreón } & 15 & 9 & 11 & 9 & 8 & 8 & 17 & 11 & 12 & 21 \\ \text { 10. AM de Aguascalientes } & 23 & 13 & 24 & 5 & 17 & 2 & 9 & 14 & 15 & 18 \\ \text { 11. Ciudad Juärez } & 11 & 3 & 21 & 22 & 7 & 22 & 26 & 12 & 13 & 20 \\ \text { 12. AM de León } & 6 & 13 & 18 & 19 & 22 & 22 & 4 & 10 & 11 & 5 \\ \text { 13. Hermosillo } & 13 & 7 & 17 & 15 & 10 & 8 & 27 & 20 & 17 & 7 \\ \text { 14. AM de Monclova } & 2 & 13 & 5 & 27 & 24 & 16 & 21 & 24 & 24 & 24 \\ \text { 15. AM de Tijuana } & 19 & 4 & 12 & 23 & 4 & 22 & 30 & 15 & 9 & 15 \\ \text { 16. AM de Cuernavaca } & 7 & 13 & 29 & 30 & 26 & 22 & 13 & 5 & 5 & 24 \\ \text { 17. Mexicali } & 29 & 6 & 9 & 6 & 2 & 16 & 29 & 27 & 16 & 8 \\ \text { 18. Chihuahua } & 16 & 5 & 20 & 8 & 15 & 8 & 24 & 17 & 18 & 11 \\ \text { 19. AM de Celaya } & 14 & 13 & 13 & 24 & 21 & 22 & 2 & 13 & 14 & 24 \\ \text { 20. AM de Mérida } & 18 & 13 & 8 & 16 & 25 & 30 & 28 & 26 & 27 & 4\end{array}$




\begin{tabular}{lrrrrrrrrrr} 
21. AM de Veracruz & 17 & 13 & 1 & 14 & 12 & 8 & 18 & 22 & 25 & 12 \\
22. AM de Tampico & 9 & 13 & 14 & 17 & 20 & 2 & 12 & 21 & 23 & 16 \\
23. Matamoros & 20 & 1 & 27 & 26 & 13 & 22 & 22 & 19 & 19 & 14 \\
24. AM de Coatzacoalcos & 1 & 13 & 22 & 13 & 3 & 22 & 25 & 23 & 26 & 19 \\
25. AM de Reynosa & 12 & 2 & 19 & 25 & 27 & 16 & 19 & 25 & 21 & 13 \\
26. Durango & 5 & 13 & 4 & 29 & 28 & 8 & 15 & 28 & 28 & 17 \\
27. Irapuato & 3 & 13 & 15 & 18 & 14 & 16 & 5 & 16 & 20 & 24 \\
28. Morelia & 25 & 13 & 10 & 28 & 30 & 8 & 8 & 18 & 22 & 9 \\
29. Mazatlán & 10 & 13 & 6 & 4 & 5 & 16 & 20 & 29 & 30 & 1 \\
30. Culiacán & 4 & 13 & 3 & 2 & 6 & 22 & 23 & 30 & 29 & 10 \\
\hline
\end{tabular}

Fuente: Cuadro Al. 


\section{CUADRO A3}

\section{Indicadores de ventajas competitivas dinámicas}

\begin{tabular}{|c|c|c|c|c|c|c|c|c|c|c|c|c|}
\hline Ciudad & $P P T$ & Sueldos & Capital & Población & Alumnos & Calidad & Parques & IDE & $J M E$ & Crédito & Ingresos & Exporta \\
\hline México & 9.66 & 19.05 & -17.50 & 1.92 & -4.58 & 0.31 & 7.67 & 0.003 & 2.68 & -68.60 & 30.98 & 21.64 \\
\hline Ciudades & 14.32 & 27.72 & -16.20 & 2.46 & -8.88 & 0.36 & 9.33 & 0.004 & 10.19 & -45.85 & 35.13 & 22.47 \\
\hline I. AM Ciudad de México & 20.32 & 36.20 & -17.65 & 1.78 & -2.11 & 0.42 & 1.89 & 0.011 & 1.15 & -59.53 & 22.73 & 10.99 \\
\hline 2. AM de Monterrey & 10.82 & 32.11 & 1.26 & 2.67 & $-4,82$ & 0.40 & 9.75 & -0.005 & 7.82 & 8.91 & 98.18 & 17.32 \\
\hline 3. AM de Guadalajara & 43.22 & 37.88 & -2.68 & 2.38 & 1.78 & 0.33 & 4.98 & -0.039 & 6.07 & 6.56 & 9 & 14.03 \\
\hline 4. AM de Puebla & 54.13 & 6.86 & -38.97 & 2.74 & -17.88 & 0.47 & 10.33 & -0.015 & 0.00 & -8.58 & 120.81 & 12.01 \\
\hline 5. AM de Saltillo & 15.72 & 27.35 & -51.46 & 3.41 & 2.90 & 0.44 & 9.07 & 0.178 & 18.80 & -50.28 & 77.47 & 50.34 \\
\hline 6. AM de Toluca & 32.95 & 35.37 & -43.73 & 4.13 & -31.90 & 0.47 & 12.37 & 0.092 & 0.00 & -21.67 & 91.39 & 36.34 \\
\hline 7. AM de San Luis Potosí & sí 26.48 & 29.42 & -11.96 & 3.11 & -15.24 & 0.44 & 14.84 & -0.012 & 0.00 & -13.66 & 73.75 & 28.69 \\
\hline 8. AM de Querétaro & 41.75 & 35.62 & -38.16 & 3.83 & 16.74 & 0.40 & 43.98 & 0.010 & 0.00 & -3.76 & 239.64 & 22.21 \\
\hline 9. AM de Torreón & 42.46 & 34.40 & 72.05 & 2.02 & -6.46 & 0.42 & 21.94 & -0.081 & 15.72 & -54.32 & 84.76 & 26.55 \\
\hline 10. AM de Aguascalientes & 68.64 & 52.68 & 190.87 & 3.51 & 7.76 & 0.39 & -3.27 & 0.101 & 0.00 & -74.47 & 181.27 & 55.32 \\
\hline 11. Ciudad Juárez. & 3.39 & 10.38 & 25.02 & 4.14 & 13.38 & 0.27 & -3.05 & -0.020 & 3.76 & -4.24 & 84.59 & 40.17 \\
\hline 12. AM de León & -2.20 & 62.10 & 9.70 & 3.18 & 61.43 & 0.32 & 2.97 & -0.091 & 0.00 & 51.41 & 61.81 & 3.45 \\
\hline 13. Hermosillo & -22.42 & 12.64 & -21.30 & 3.24 & -39.12 & 0.45 & -14.41 & -0.017 & 18.49 & 111.41 & 166.60 & 50.86 \\
\hline 14. AM de Monclova & 97.38 & 17.55 & -52.93 & 1.46 & 16.54 & 0.42 & 0.00 & -0.231 & 0.00 & -36.11 & 21.46 & 6.35 \\
\hline 15. AM de Tijuana & -19.37 & 18.31 & -31.03 & 5.44 & -0.42 & 0.23 & 36.57 & -0.026 & 3.53 & -26.41 & 82.82 & 41.28 \\
\hline 16. AM de Cuernavaca & -10.22 & 20.01 & -9.58 & 4.41 & -14.29 & 0.42 & -14.32 & -0.048 & 0.00 & 140.20 & 180.11 & 1.03 \\
\hline
\end{tabular}




\begin{tabular}{lrrrrrrrrrrrr} 
17. Mexicali & 33.66 & 32.63 & 48.70 & 2.41 & 9.47 & 0.39 & 25.25 & 0.044 & 17.06 & -56.36 & 108.61 & 58.63 \\
18. Chihuahua & -18.41 & 21.89 & 2.52 & 2.71 & -17.25 & 0.42 & -37.91 & -0.055 & 19.57 & -29.51 & 144.60 & 18.67 \\
19. AM de Celaya & -3.59 & 15.86 & 21.87 & 2.73 & 20.70 & 0.34 & 25.86 & 0.014 & 0.00 & 12.12 & 100.95 & 2.26 \\
20. AM de Mérida & 4.40 & 14.72 & -22.61 & 2.80 & -9.64 & 0.32 & 20.86 & 0.028 & 0.00 & -11.73 & 95.39 & 18.55 \\
21. AM de Veracruz & 80.28 & 7.97 & 1.78 & 2.84 & -24.65 & 0.40 & 24.43 & 0.273 & 0.00 & 29.80 & 44.45 & -5.38 \\
22. AM de Tampico & 14.85 & 27.52 & 72.57 & 1.87 & -47.45 & 0.40 & -2.20 & 0.084 & 0.00 & 5.20 & 103.54 & -14.66 \\
23. Matamoros & 36.31 & 38.94 & 2.92 & 3.55 & 11.38 & 0.29 & 26.84 & -0.005 & 0.59 & -14.77 & 75.40 & 44.32 \\
24. AM de Coatzacoalcos & 16.02 & -19.22 & 32.92 & 1.87 & 4.51 & 0.14 & 5.68 & -0.300 & 0.00 & -71.33 & 50.22 & 18.52 \\
25. AM de Reynosa & 28.82 & 31.73 & 112.49 & 3.53 & 23.57 & 0.28 & -64.01 & -0.058 & 5.29 & -26.19 & 254.96 & 51.29 \\
26. Durango & 60.07 & 35.94 & 85.41 & 2.33 & -4.68 & 0.40 & 15.68 & 0.224 & 0.00 & 3.32 & 195.49 & 16.01 \\
27. Irapuato & -7.43 & 25.70 & -35.88 & 2.42 & 266.30 & 0.26 & -6.94 & -0.082 & 0.00 & -54.68 & 41.15 & -2.35 \\
28. Morelia & 44.05 & 49.56 & -9.93 & 2.90 & -26.55 & 0.40 & 12.12 & 0.037 & 0.00 & 18.68 & 143.01 & 20.16 \\
29. Mazaulán & 99.42 & 28.41 & 82.61 & 2.42 & -12.15 & 0.11 & 11.90 & -0.138 & 0.00 & -78.88 & 38.17 & 0.98 \\
30. Culiacán & 22.57 & 36.23 & 17.18 & 2.97 & -47.20 & 0.38 & 1.59 & -0.264 & 0.00 & -72.90 & 65.01 & 30.25 \\
\hline
\end{tabular}

Fuentes: Cálculos elaborados con información de INEGr, Censos de población y vivienda 1990 y 2000, Censos industrial y de servicios, 1989, 1994 y 1999, Finanzas públicas municipales, 1988-1998, Sistema de Cuentas Nacionales de México y página web, Banco de lnformación Económica; Consejo Nacional de Población, Índice de Marginación por Localidad, 1990-1995; Poder Ejecutivo Federal, Sexto informe de gobierno, 1994 y 2000, anexo; Sistema Mexicano de Promoción de Parques Industriales, página web; y Mercamétrica Ediciones, Mercamétrica de 80 ciudades mexicanas, 1990 y 1995. 
CUADRO A4

Ordenamiento de los indicadores de ventajas competitivas dinámicas por ciudad

\begin{tabular}{lrrrrrrrrrrrrrr}
\hline Ciudad & Competil. & PPr & \multicolumn{1}{c}{ Sueldos } & Capital & Población & Alumnos & Calidad & Parques & DE & IME & Crédito & Ingresas & Exporta \\
\hline 1. AM Ciudad de México & 24 & 17 & 7 & 21 & 29 & 13 & 18 & 20 & 11 & 11 & 26 & 30 & 22 \\
2. AM de Monterrey & 21 & 21 & 13 & 16 & 20 & 17 & 14 & 15 & 14 & 6 & 7 & 13 & 18 \\
3. AM de Guadalajara & 1 & 8 & 5 & 17 & 24 & 12 & 19 & 18 & 20 & 7 & 8 & 14 & 20 \\
4. AM de Puebla & 4 & 6 & 29 & 27 & 17 & 23 & 8 & 14 & 16 & 13 & 13 & 10 & 21 \\
5. AM de Saltillo & 15 & 19 & 18 & 29 & 9 & 14 & 17 & 16 & 3 & 2 & 22 & 19 & 5 \\
6. AM de Toluca & 12 & 13 & 10 & 28 & 4 & 27 & 4 & 11 & 5 & 13 & 17 & 18 & 9 \\
7. AM de Sanı Luis Potosín & 19 & 15 & 15 & 20 & 12 & 21 & 10 & 10 & 15 & 13 & 15 & 17 & 11 \\
8. AM de Querétaro & 8 & 10 & 9 & 26 & 5 & 7 & 24 & 1 & 12 & 13 & 11 & 3 & 13 \\
9. AM de Torreón & 5 & 9 & 11 & 6 & 26 & 16 & 15 & 7 & 24 & 5 & 23 & 15 & 12 \\
10. AM de Aguascalientes & 2 & 4 & 2 & 1 & 8 & 11 & 20 & 25 & 4 & 13 & 29 & 4 & 2 \\
11. Ciudad Juárez & 9 & 23 & 27 & 9 & 3 & 10 & 21 & 24 & 18 & 9 & 12 & 23 & 8 \\
12. AM de Ieón & 16 & 24 & 1 & 12 & 11 & 2 & 29 & 19 & 26 & 13 & 3 & 24 & 24 \\
13. Hermosillo & 11 & 30 & 26 & 22 & 10 & 28 & 3 & 28 & 17 & 3 & 2 & 5 & 4 \\
14. AM de Monclova & 25 & 2 & 23 & 30 & 30 & 3 & 28 & 22 & 28 & 13 & 21 & 29 & 23 \\
15. AM de Tijuana & 6 & 29 & 22 & 24 & 1 & 20 & 11 & 2 & 19 & 10 & 19 & 28 & 7 \\
16. AM de Cuernavaca & 30 & 27 & 21 & 18 & 2 & 24 & 7 & 27 & 21 & 13 & 1 & 8 & 26 \\
17. Mexicali & 3 & 12 & 12 & 7 & 23 & 6 & 25 & 5 & 7 & 4 & 25 & 11 & 1 \\
18. Chihuahua & 27 & 28 & 20 & 14 & 19 & 22 & 9 & 29 & 22 & 1 & 20 & 6 & 15 \\
19. AM de Celaya & 26 & 25 & 24 & 10 & 18 & 4 & 27 & 4 & 10 & 13 & 6 & 12 & 25
\end{tabular}




\begin{tabular}{|c|c|c|c|c|c|c|c|c|c|c|c|c|c|}
\hline 20. AM de Mérida & 18 & 22 & 25 & 23 & 16 & 18 & 13 & 8 & 9 & 13 & 14 & 16 & 16 \\
\hline 21. AM de Veracruz & 29 & 3 & 28 & 15 & 15 & 25 & 6 & 6 & 1 & 13 & 4 & 26 & 29 \\
\hline 22. AM de Tampico & 23 & 20 & 17 & 5 & 28 & 29 & 2 & 23 & 6 & 13 & 9 & 9 & 30 \\
\hline 23. Matamoros & 14 & 11 & 4 & 13 & 6 & 9 & 22 & 3 & 13 & 12 & 16 & 21 & 6 \\
\hline 24. AM de Coatzacoalcos & 28 & 18 & 30 & 8 & 27 & 8 & 23 & 17 & 30 & 13 & 27 & 20 & 17 \\
\hline 25. AM de Reynosa & 7 & 14 & 14 & 2 & 7 & 5 & 26 & 30 & 23 & 8 & 18 & 1 & 3 \\
\hline 26. Durango & 13 & 5 & 8 & 3 & 25 & 15 & 16 & 9 & 2 & 13 & 10 & 2 & 19 \\
\hline 27. Irapuato & 22 & 26 & 19 & 25 & 22 & 1 & 30 & 26 & 25 & 13 & 24 & 25 & 28 \\
\hline 28. Morelia & 17 & 7 & 3 & 19 & 14 & 26 & 5 & 12 & 8 & 13 & 5 & 7 & 14 \\
\hline 29. Mazatlán & 10 & 1 & 16 & 4 & 21 & 19 & 12 & 13 & 27 & 13 & 30 & 27 & 27 \\
\hline 30. Culiacán & 20 & 16 & 6 & 11 & 13 & 30 & 1 & 21 & 29 & 13 & 28 & 22 & 10 \\
\hline
\end{tabular}

Fuente: Cuadro A3. 


\section{Bibliografía}

Ballance, Robert (1987), International Industry and Business, Londres, Allen and Unwin.

Begg, lain (1999), "Cities and Competitiveness", Urban Studies, vol. 36, núm. 5-6, pp. 795-809.

Begovic, Boris (1991), "The Economic Approach to Optimal City Size", Progress in Planning, vol. 36, núm. 2, pp. 93-161.

Beristain, Javier (1991), "Las ventajas competitivas de México", en Luis Mercado (comp.), Competitividad, Segundo Seminario de El Economista, México.

Best, Michael (1990), The New Competition, Cambridge, Harvard University Press.

Blair, John (1995), Local Economic Development, California, Sage.

Bovaird, Tony (1992), "Local Economic Development and the City", Urban Studies, vol. 29, núm. 3-4, pp. 343-368.

Budd, Leslie (1998), "Territorial Competition and Globalisation: Scylla and Changbdis of European Cities", Urban Studies, vol. 35, núm. 4, pp. 663-685.

Busquets, Juan (1993), "Perspectiva desde las ciudades", Ciudad y Territorio. Estudios Territoriales, vols. 95-96, pp. 163-174.

Call, Steven y William Holahan (1985), Microeconomia, México, Grupo Editorial Iberoamérica.

Casar, José (1994), "El sector manufacturero y la cuenta corriente. Evolución reciente y perspectivas", en Fernando Clavijo y José Casar (comps.), La industria mexicana en el mercado mundial, tomo I, México, Fondo de Cultura Económica/El Trimestre Económico (Lecturas, 80).

CEPAL (1995), Análisis de la competitividad de las naciones. Versión 2.0. Manual de uso, Santiago de Chile.

Collinge, Chris (1992), "The Dynamics of Local Intervention: Economic Development and the Theory of Local Government", Urban Studies, vol. 29, núm. 1, pp. 57-75.

Cox, Kevin (1995), "Globalisation, Competition and the Politics of Local Economic Development”, Urban Studies, vol. 32, núm. 2, pp. 213-224.

Chapman, Keith y David Walker (1991), Industrial Location, Oxford, Basil Blackwell.

Cheshire, Peter e Ian Gordon (1993), "European Integration: Territorial Competition in Theory and Practice", documento de trabajo núm. 2, Reading, Inglaterra, University of Reading, Centre for Study of Advanced European Regions.

Dicken, Peter (1992), Global Shifl, Nueva York, The Guilford Press.

Dussel, Enrique (1995), "El cambio estructural del sector manufacturero mexicano, 1988-1994", Comercio Exterior, vol. 45, núm. 6, pp. 460-469.

Fajnzylber, Fernando (1988), "Competitividad internacional: evolución y lecciones", Revista de la CEPAL, vol. 36, pp. 12-26.

Gilbert, Alan (1998), "World Cities and the Urban Future: The View from Latin America”, en Fu-chen Lo y Yue-man Yeung (eds.), Globalization and the World of Large Cities, Tokio, United Nations University Press.

González, Jaime y Abelardo Mariña (1992), 'Formación de capital, productividad y costos. Relaciones generales", Análisis Económico, vol. 10, núm. 20, pp. 3-17. 
Goodall, Brian (1977), La economia de las zonas urbanas, Madrid, Instituto de Estudios de Administración Local.

Gordon, Ian (1999), "Internationalization and Urban Competition", Urban Studies, vol. 36, núms. 5-6, pp. 1001-1006.

Guerrero, Diego (1996), "La técnica, los costos, la ventaja absoluta y la competitividad", Comercio Exterior, vol. 46, núm. 5, pp. 400-407.

Guzmán, Alenka (1997), "Productividad y especialización manufactureras en México, Canadá y Estados Unidos, 1972-1994", Comercio Exterior, vol. 47, núm. 3, pp. 179-191.

Harvey, David (1989), The Condition of Postmodernity, Oxford, Blackwell.

Healey, Michael y Philip Dunham (1994), "Changing Competitive Advantage in a Local Economy: The Case of Coventry, 1971-1990", Urban Studies, vol. 31, núm. 8, pp. 1279-1301.

Hirsch, Werner, (1977), Análisis de economía urbana, Madrid, Instituto de Estudios de Administración Local.

INEGI (1995), Indicadores de competitividad de la economia mexicana, Aguascalientes, Instituto Nacional de Estadística, Geografia e Informática.

Institute for Management Development (2001), World Competitiveness Yearbo$o k$, Lausana.

Isard, Walter (1973), Métodos de análisis regional, Barcelona, Ariel.

Johnson, Bryan, Kim Holmes y Melanie Kirkpatrick (1998), 1998 Index of Economic Freedom, Washington, The Heritage Foundation/The Wall Street Journal.

Kresl, Peter (1998), "La respuesta de la economía urbana al Tratado de Libre Comercio de América del Norte: planificar para la competitividad", Economia, Sociedad y Territorio, vol. 1, núm. 4, pp. 695-722.

(1995), "The Determinants of Urban Competitiveness", en Peter Kresl y Gunnar Gappert (eds.), North America Cities and the Global Economy: Challenges and Opportunities, Londres, Sage Publications.

__ y Balwant Singh (1999), "Competitiveness and the Urban Economy: Twenty-four Large US Metropolitan Areas", Urban Studies, vol. 36, núms. 5-6, pp. 1017-1027.

Krugman, Paul (1996), "Making Sense of the Competitiveness Debate", $O x$ ford Reriew of Economic Policy, vol. 12, núm. 3, pp. 483-499.

- (1994), "Competitiveness: a Dangerous Obsession", Foreign Affairs, vol. 74, núm. 2, pp. 28-44.

- (1992), "La competitividad económica: mitos y realidades", Economia Abierta, vol. 1, pp. 1-23.

- (1991), International Economics, Trade and Policy, Nueva York, Harper Collins Publishers.

- $y$ Anthony Venables (1990), "Integración y competitividad de la industria periférica", Estudios Económicos, vol. 5, núm. 2, pp. 263-286.

Lever, William (1999), "Competitive Cities in Europe", Urban Studies, vol. 36, núms. 5-6, pp. 1029-1044.

e Ivan Turok (1999), "Competitive Cities: Introduction to the Review", Urban Studies, vol. 36, núms. 5-6, pp. 791-793.

Maddala, Gregory (1996), Introducción a la econometria, México, Prentice Hall Interamericana. 
Malecki, Edward (1997), Technology and Economic Development: The Dynamics of Local, Regional and National Competitiveness, Harlow, Inglaterra, Longman.

Márquez, Carlos (1994), "La competitividad de la industria textil", en Fernando Clavijo y José Casar (comps.), La industria mexicana en el mercado mundial, tomo 2, México, Fondo de Cultura Económica/El Trimestre Económico (Lecturas, 80).

Marsh, Ian y Stephen Tokarik (1994), "Competitiveness Indicators: A Theoretical and Empirical Assessment", documento de trabajo núm. 94/29, Nueva York, Fondo Monetario Internacional.

Mattar, Jorge (1996), "Desempeño exportador y competitividad internacional: algunos ejercicios CAN para México", Comercio Exterior, vol. 46, núm. 3 , pp. 193-202.

Millán, Henio (1996), La competitividad de la industria manufacturera del Estado de México, Zinacantepec, El Colegio Mexiquense (Seminarios de Investigación).

Moreno, Adrián (1995), "Calidad de vida en el sistema metropolitano de San Luis Potosí", en Carlos Garrocho y Jaime Sobrino (coords.), Sistemas metropolitanos. Nuevos enfoques y prospectiva, Zinacantepec, El Colegio Mexiquense/Secretaria de Desarrollo Social, pp. 483-530.

Noyola, Pedro (1991), "La competitividad de la economía mexicana", en Luis Mercado (comp.), Competitividad, Segundo Seminario de ElEconomista, México.

Notimex (2001), "Globalización", Reforma, sección internacional, enero 9.

Peeters, Dominique, Jaques Francois Thiesse e Isabelle Thomas (1998), "Transportation Networks and the Location of Human Activities", Geographical Analysis, vol. 30, núm. 4, pp. 355-371.

Pindyck, Robert y Daniel Rubinfeld (2001), Econometria: modelos y pronósticos, Méxiço, MacGraw-Hill.

Porter, Michael (1997), "La ventaja competitiva", documento presentado en el Seminario Internacional I a Ventaja Competitiva, México, IBM Educación. - (1996), "Competitive Advantage, Agglomeration Economies, and Regional Policy", International Regional Science Review, vol. 19, núms. 1-2, pp. 85-94.

- (1993), Estrategia competitiva, México, Compañía Editorial Continental.

(1991), La ventaja competitiva de las naciones, Buenos Aires, Vergara.

Ramírez, José Carlos y Ali Hauser (1996), "La localización industrial en los sistemas rígidos y flexibles de producción: un punto de partida para nuevos desarrollos teóricos", Economía Mexicana, nueva época, vol. 5, núm. 1, pp. 99-129.

Ramírez, María Delfina y Robert Wallace (1998), "Competitividad, productividad y ventaja comparativa", Investigación Económica, vol. 225, pp. 17-82.

Richardson, Harry (1986), Economia regional y urbana, Madrid, Alianza Editorial (Textos).

Robinson, Guy (1998), Methods and Techniques in Human Geography, Baffis Lane, Inglaterra, John Wiley \& Sons.

Rogerson, Robert (1999), "Quality of Life and City Competitiveness", Urban Studies. vol. 36, núms. 5-6, pp. 969-985. 
Roper, Stephen (1998), "Plan Size and Industry-Mix Effects on UK Regional Productivity, Wage Costs and Operating Surplus", Regional Studies, vol. 32, núm. 4, pp. 325-332.

Rosen, Harvey (1995), Public Finance, Chicago, Irwin.

Samuelson, Paul (1965), Foundations of Economic Analysis, Nueva York, Atheneum.

Savitch, Harold (1998), "Global Challenge and Institutional Capacity", Administration and Society, vol. 30, núm. 3, pp. 248-273.

Sección In ternacional (1995), "Comercio internacional y nuevas realidades competitivas", Comercio Exterior, vol. 45, núm. 8, pp. 623-626.

Smith, David (1975), Patterns in Human Geography, Harmondsworth, Inglaterra, Penguin Books.

Sobrino, Jaime (2000), Productividad y ventajas competitivas en el sistema urbano nacional, México, Universidad Nacional Autónoma de México, tesis de doctorado en Urbanismo.

The Economist (1998), vol. 346, núm. 8053, pp. 36-39.

The World Bank (2000), Entering the 2Ist Century, Nueva York, Oxford University Press.

UNCTAD (2000), The Competitiveness Challenge: Transnational Corporations and Industrial Restructuring in Developing Countries, Nueva York, Naciones Unidas.

Unger, Kurt (1993), "Productividad, desarrollo tecnológico y competitividad exportadora en la industria mexicana", Economía Mexicana, nueva época, vol. 2, núm. 1, pp. 183-237.

Utton, M. (1975), La concentración industrial, Madrid, Alianza Editorial.

Varian, Hal (1994), Microeconomia intermedia, Barcelona, Antoni Bosch Editor. Vega, Fernando (2000), Economia y juegos, Barcelona, Antoni Bosch Editor. 